Research Article

\title{
Physical Modeling Test on Deformation and Failure of Rock Slope with New Support System
}

\author{
Zhigang Tao $\mathbb{D}^{1,2}$ Tongxing Zhang, ${ }^{1,2}$ Daoyong Zhu, ${ }^{1,2}$ Weili Gong, ${ }^{1,2}$ and Manchao He ${ }^{1,2}$ \\ ${ }^{1}$ State Key Laboratory for Geomechanics \& Deep Underground Engineering, China University of Mining \& Technology, \\ Beijing 100083, China \\ ${ }^{2}$ School of Mechanics and Civil Engineering, China University of Mining \& Technology, Beijing 100083, China
}

Correspondence should be addressed to Zhigang Tao; taozhigang@263.net

Received 13 April 2020; Revised 19 May 2020; Accepted 28 May 2020; Published 29 June 2020

Academic Editor: Tiago Ferreira

Copyright (c) 2020 Zhigang Tao et al. This is an open access article distributed under the Creative Commons Attribution License, which permits unrestricted use, distribution, and reproduction in any medium, provided the original work is properly cited.

\begin{abstract}
In order to explore the monitoring and control method of rock slope, indoor physical model testing of collapse control and monitoring were carried out with the example of a rock slope collapse area project in Jietai Temple in Beijing, China, as the prototype. Based on the similarity theory, in this study, a new structural support with Negative Poisson's Ratio bolt and flexible anchored net was utilized to reinforce the rock slope. Following a graded loading sequence, the collapse failure characteristics and the overall control effect of energy absorption reinforcement measures were explored. The experimental results demonstrated that the entire process of slope collapse presented four distinct stages of failure: fracture generation, fracture propagation, partial collapse, and overall collapse. The full-field displacement nephogram and the displacement monitoring point of the collapse area indicated that the large deformation and failure of the collapsed surrounding rock were effectively controlled, while the Negative Poisson's Ratio bolt and the flexible anchored net had good reinforcement effects. The experimental stress record presented that the change of pressure curve was an apparent regularity in the entire process of slope collapse, which reflects the change state of internal force of surrounding rock; it includes the function of monitoring of slope collapse. It was indicated that the Negative Poisson's Ratio bolt along with the large-deformation flexible anchored net had good reinforcement monitoring effect on the rock slope collapse disaster.
\end{abstract}

\section{Introduction}

Under the effects of rainfall, earthquake, and weathering, the strength of rock mass becomes weak, causing the engineering collapse [1-4], which was extremely destructive and with high potential for dangers of tunnel, roadway, and slope [5-9]. The failure of rock slope with multijoints was a kind of prominent geological hazards; its failure mode is complicated, and the treatment is difficult [10-12]. At present, the treatment measures were mainly based on the traditional support methods such as anchorage. Its resistance to slope mass large deformation and anti-impact were poor. Its deficiency was a major scientific problem limiting the on-site safety of the slope. Therefore, it is necessary to conduct indepth research.

Currently, most of the research studies on slope collapse were on site. Harry used reinforced piles to increase slope stability [13]. Shi et al. utilized prestressed cable bolt and concrete frame to reinforce the collapse of steep-high slope of hydropower station [14]. Dong et al. researched the collapse of high cutting slope with horizontal soft-hard alternant strata and adopted anchorage, bolt-shotcrete for reinforcement [15]. Lin et al. researched reinforcement measures for the high and steep slope with weak rock mass structures with a rock bolt and long anchor reinforcement measures [16]. The treatment method of slope collapse was mainly based on bolt and bolt-shotcrete support; its materials are all common rebar. It has the low deformation characteristics which are difficult to meet the safety requirements of slope treatment. He et al. [17-20] developed a new type of structural bolt; it was used in roadway and slope reinforcement and has achieved good results. The structural bolt called "Negative Poisson's Ratio bolt (NPR bolt)" has ultra-high-energy-absorbing capacity by deforming with an 
extraordinarily large elongation at high constant resistance [21]. To sum up, it was found that most of the control and treatment of slope collapse were carried out in the order of pretreatment, emergence, and retreatment. At present, the main indoor research method was physical model test; it has the strong intuitive characteristics, and the qualitative or quantitative analysis that is applied to the rock slope stability analysis [22-25]. Friedmann et al. studied the physical behavior of rock debris flow after collapse by model experiment [26]. Alzo'ubi et al. studied the effect of tensile strength on the toppling failures of the rock collapse by centrifuge test [27]. Bourrier et al. compared and analyzed the rebound model of the rock collapse by simulation test [28]. By means of shaking table tests associated with numerical analyses, $\mathrm{Li}$ et al. discussed the effect of seismic wave on response of jointed antidip rock slopes [29]. At present, the physical model test mainly studied the failure mechanism of the collapse, but there was no in-depth study on the collapse support.

This paper takes Jietai Temple in Beijing, China, as the research object. Aiming at the problem of slope collapse, the paper proposes a support method utilizing "NPR bolt + anchored net." On the basis of field application, we carried out the physical model test, the deformation characteristics were studied under the condition of the new support system, and the improved supporting measures and monitoring methods were put forward, which provided a theoretical reference for the comprehensive prevention and control of the multijoint slope.

\section{Geological Settings}

The geological structure around Jietai Temple in Mentougou, Beijing, China, is complex and rich in minerals, such as clay and limestone. Especially in the last ten years, with the application of modern mining tools, the disturbance of large-scale mining activities to mountain was further intensified, which led to rock mass loosening, local goaf collapses, and cracks.

As shown in Figure 1, Jietai Temple was located at the northern foot of Ma'an Mountain in the southwestern mountainous area of Beijing. Its front was a ridge with a north-south direction, located in the transition zone inbetween middle-low mountain and plain, while belonging to the low mountain denudation geomorphic unit. The southern Ma'anshan Mountains were generally nearly eastwest, slightly inverse "S" curve, and the ridges were low towards the east and high towards the west. According to regional geological data analysis, the average elevation of the collapse mass was about $46 \mathrm{~m}$, the slope direction is $254^{\circ}$, the slope is about $80^{\circ}$, and the width is about $52 \mathrm{~m}$.

As shown in Figure 2, the upper lithology of the slope area was sandy shale, which belonged to soft rock, with joint fissures in rock mass and thick weathering layer. The range of dangerous rock mass was mainly concentrated on the steep slope surface, with a thickness of approximately $1 \mathrm{~m}$. The slope rock mass structure was unstable and the structural plane was developed. These structural planes cut the rock mass into lump structures, and there were local rock collapses and fell blocks. The lower part was sandstone, with dense and hard medium-thick layers, which could be utilized as a stable bearing layer; the lithology of the collapse area was mainly sandy shale.

This geological section reflects the typical characteristics of the surrounding rock of the slope in the area around Jietai Temple. The surrounding rock has obvious joint fissures, and the slope is in an unstable state with potential danger of collapse. The construction and design of the model test can better simulate the structural characteristics of the surrounding rock of the slope and greatly enhance the authenticity of the physical model test, which is of representative significance for the study of the slope collapse support in the Jietai Temple area.

\section{Model Test}

\subsection{Model Design}

3.1.1. Test Device. In this experiment, the geological conditions of rocky slope surrounding Jietai Temple in Mentougou, Beijing, were taken as the research background, while the plane stress loading model experimental device of the State Key Laboratory for Geomechanics and Deep Underground Engineering, China University of Mining and Technology-Beijing, was adopted. As presented in Figure 3, the experimental system consisted of main parts, such as main engine structure and hydraulic control platform. The framework size was $3310 \mathrm{~mm} \times 970 \mathrm{~mm} \times$ $3010 \mathrm{~mm}$, which could accommodate the physical model size of $1600 \mathrm{~mm} \times 400 \mathrm{~mm} \times 1600 \mathrm{~mm}$. Six groups of hydraulic jacks were distributed within each boundary direction. Each hydraulic jack could be pressurized separately. The loading range of modeling the hydraulic cylinder is $0-5 \mathrm{MPa}$, realizing step-bystep loading of the physical model working face.

3.1.2. Similar Design. The section size of the site collapse was as follows: length $\times$ height $=52 \mathrm{~m} \times 46 \mathrm{~m}$; combining the size of the site collapse and the experimental model, the geometric similarity ratio of the model experiment was finally determined [30, 31]:

$$
C_{L}=\frac{L_{p}}{L_{m}}=30,
$$

where $L_{p}$ are the geometric parameters of the prototype and $L_{m}$ are the geometric parameters of the model. The similarity ratio of the bulk density was determined through indoor proportioning tests:

$$
C_{\gamma}=\frac{\gamma_{p}}{\gamma_{m}}=1,
$$

where $\gamma_{p}$ is the bulk density of the prototype; $\gamma_{m}$ is the bulk density of the model. Therefore, the stress similarity ratio was finally determined as

$$
\begin{aligned}
& C_{\sigma}=C_{L} C_{\gamma}=30, \\
& C_{\varepsilon}=C_{f}=C_{\mu}=1, \\
& C_{E}=C_{\sigma}=30,
\end{aligned}
$$

where $C_{\varepsilon}$ is the similarity ratio of strain, $C_{f}$ is the similarity ratio of friction coefficient, $C_{\mu}$ is the similarity ratio of 


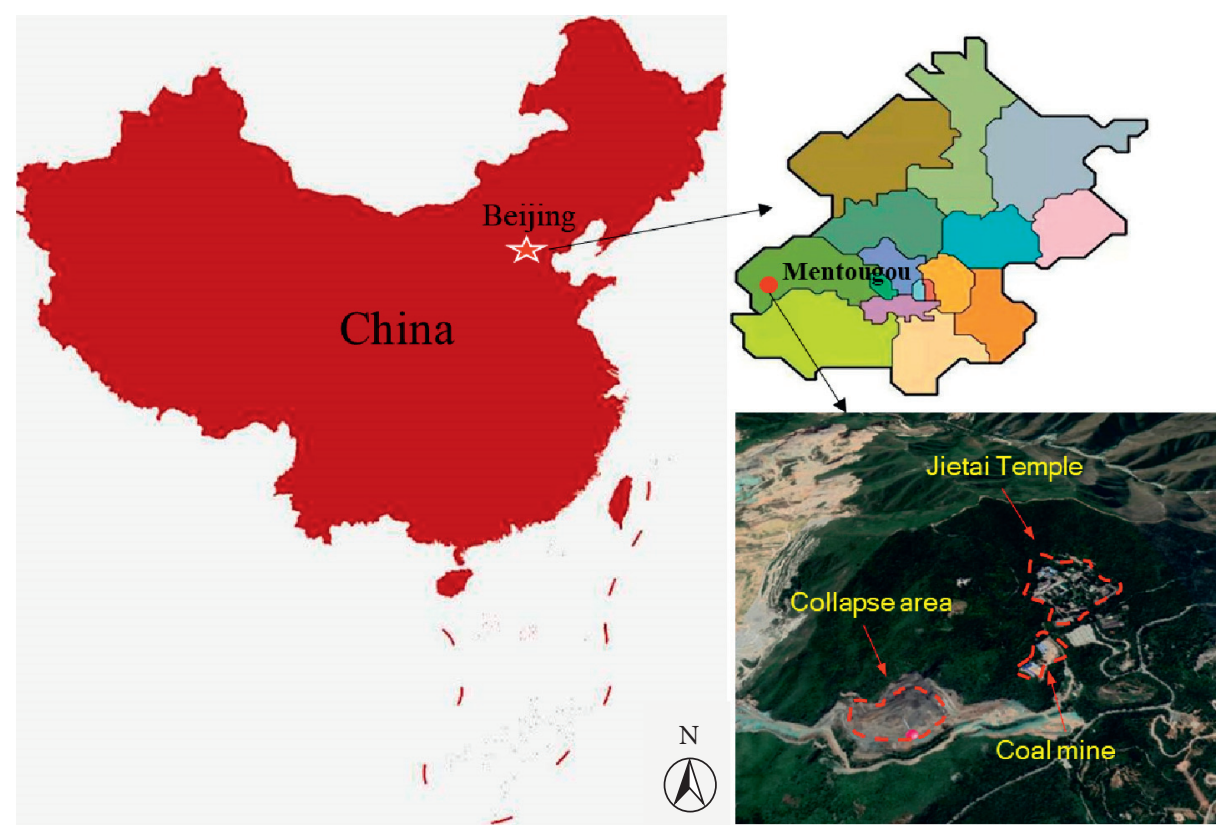

Figure 1: Location of the Jietai Temple slope.
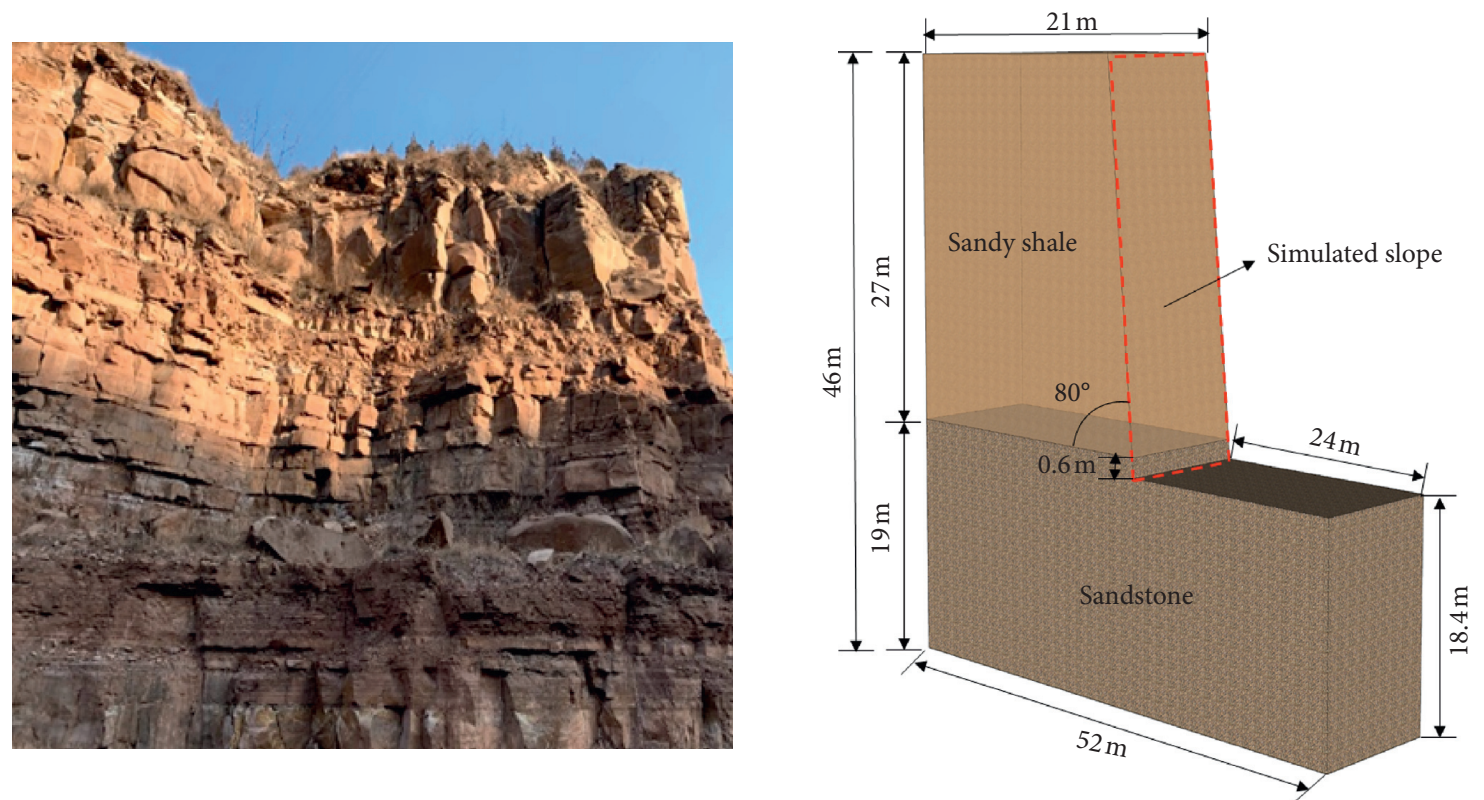

FIGURE 2: Site slope and model diagram of Jietai Temple.

Poisson's ratio, and $C_{E}$ is the similarity ratio of elastic modulus.

3.1.3. Slope Model Construction. As presented in Figure 4, the rock strata in the model were laid out by unit plates made of water, gypsum powder, fine river sand, and barite powder. The similar materials mechanics parameters meet the requirements through laboratory rock mechanics experiments, and there were slight differences that could be ignored; the mechanical parameters were presented in Table 1 .
As presented in Figure 5, the range of dangerous rock mass was mainly concentrated on the steep slope surface. Combining the actual geological conditions in the field, the structural surface and secondary fracture surface of rock layers were simulated through using the layering of unit plates made of similar materials to restore the real structure of the slope rock. The weak structural plane between each layer of unit plates could be regarded as bedding in the rock mass, and the vertical crack between unit plates could be regarded as joint fissure in the rock mass. The small-size unit plate was utilized to build slope model to simulate the joint- 


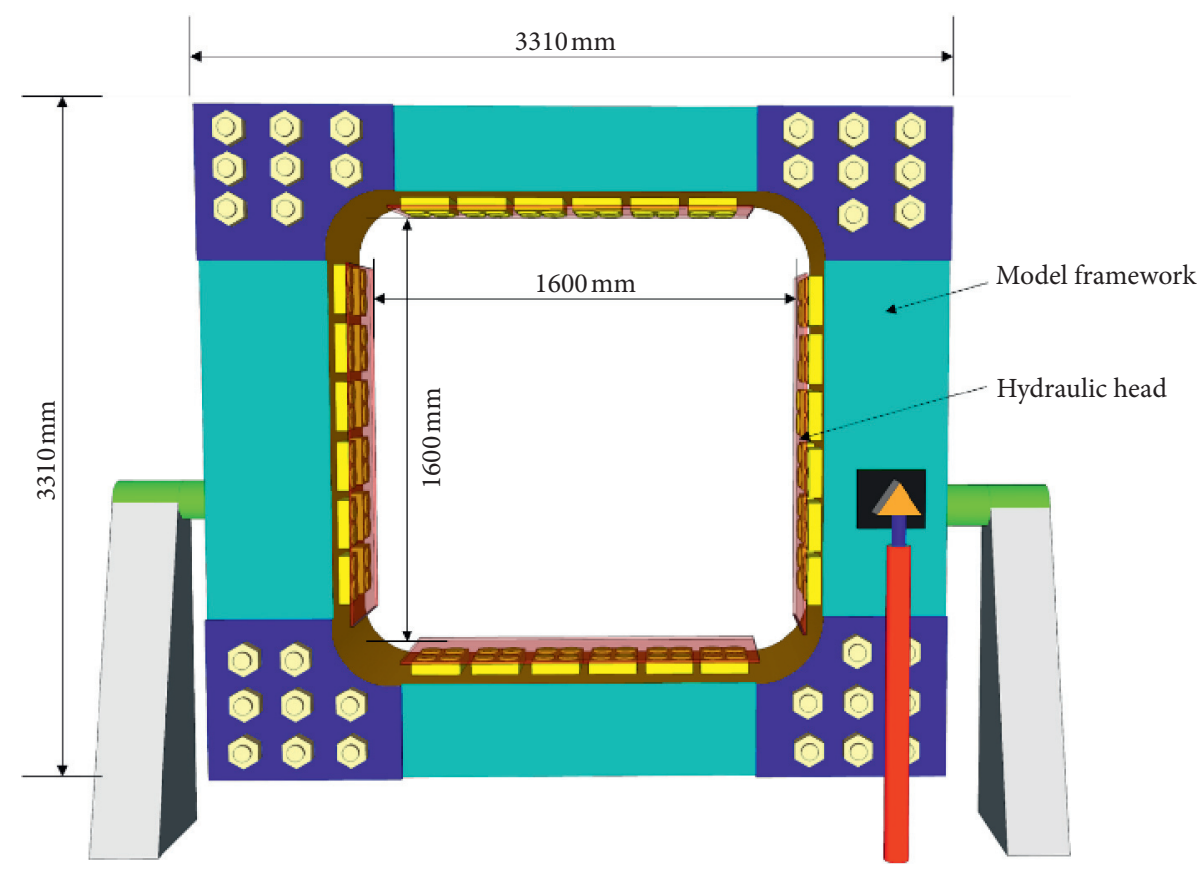

Figure 3: Plane strain loading experiment device.

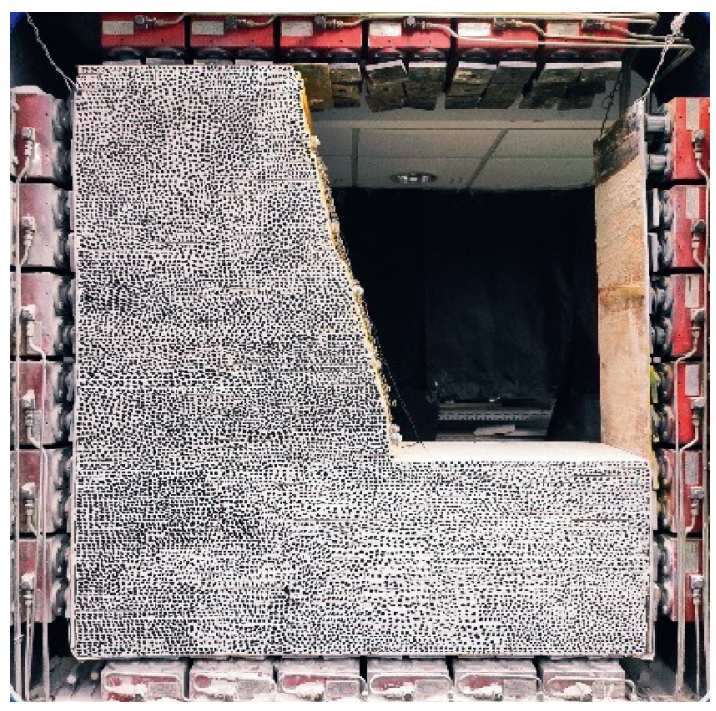

(a)

Figure 4: Physical model test diagram: (a) lateral view; (b) model geometry.

(b) intensive area in the slope fractured rock mass zone; the width of the zone was $60 \mathrm{~mm}$.

3.1.4. Load Design. In the first stage, as presented in Figure $6(\mathrm{a})$, the horizontal pressure $\sigma_{x}=0.2 \mathrm{MPa}$ and the vertical pressure $\sigma_{y}=0.2 \mathrm{MPa}$ were applied to the entire model, while the pressure remained unchanged for 20 minutes subsequently to preloading. In the second stage, as presented in Figure 6(b), the top of the model was continuously loaded step by step, with $0.1 \mathrm{MPa}$ as the loading step, and the horizontal pressure on both sides remained unchanged. Finally, horizontal pressure $\sigma_{x}=0.2 \mathrm{MPa}$ and

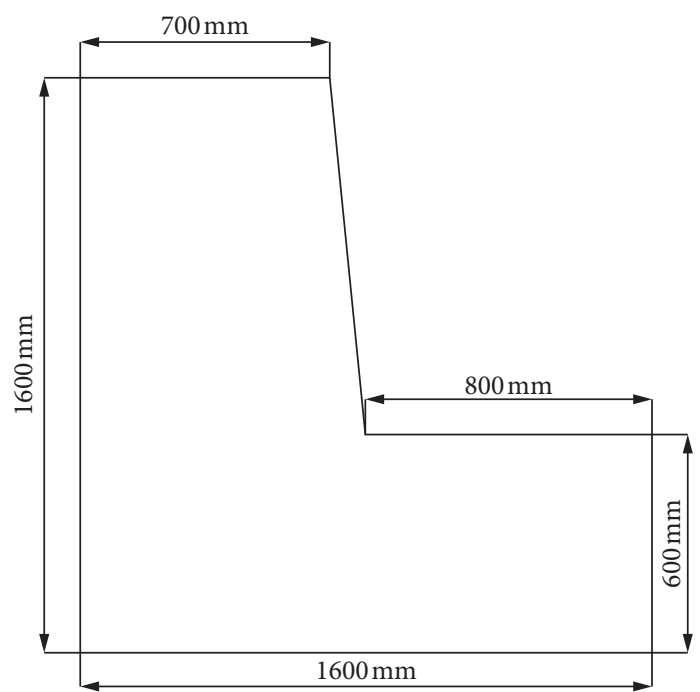

vertical pressure $\sigma_{y}=0.6 \mathrm{MPa}$ were applied to the entire model. The entire process lasted 100 minutes in five stages. The experimental loading steps are presented in Figure 6(c).

\subsection{Reinforcement Design}

\subsubsection{NPR Bolt and Its Reinforcing Principle}

(1) NPR Bolt Structure. Figure 7 presents the NPR bolt, consisting of a constant cone, a sleeve pipe, a shank rod, a bearing plate, and a tightening nut $[32,33]$. The larger end diameter of the cone was slightly bigger than the inner 
TABLE 1: Physical and mechanical parameters of rock mass and model materials.

\begin{tabular}{|c|c|c|c|c|c|c|c|c|}
\hline \multicolumn{2}{|c|}{ Lithology } & $\begin{array}{c}\text { Bulk density } \\
\left(\mathrm{kN} / \mathrm{m}^{3}\right)\end{array}$ & $\begin{array}{l}\mathrm{UCS} \\
(\mathrm{MPa})\end{array}$ & $\begin{array}{l}\text { Tensile strength } \\
(\mathrm{MPa})\end{array}$ & $\begin{array}{c}\text { Elastic modulus } \\
(\mathrm{GPa})\end{array}$ & $\begin{array}{c}\text { Internal friction } \\
\text { angle }\left({ }^{\circ}\right)\end{array}$ & $\begin{array}{c}\text { Cohesion } \\
\text { (MPa) }\end{array}$ & $\begin{array}{l}\text { Poisson's } \\
\text { ratio }\end{array}$ \\
\hline \multirow{3}{*}{$\begin{array}{l}\text { Sandy } \\
\text { shale }\end{array}$} & Prototype & 25.2 & 18.6 & 0.86 & 18.8 & 35 & 9.62 & 0.19 \\
\hline & Model & 25.9 & 0.68 & 0.03 & 0.6 & 32 & 0.34 & 0.14 \\
\hline & $\begin{array}{l}\text { Similarity } \\
\text { ratio }\end{array}$ & 1 & 27 & 29 & 31 & 1 & 28 & 1 \\
\hline \multirow{3}{*}{ Sandstone } & Prototype & 26.5 & 23.8 & 1.13 & 25.4 & 38 & 12.14 & 0.26 \\
\hline & Model & 27.1 & 0.81 & 0.04 & 0.85 & 34 & 0.42 & 0.23 \\
\hline & $\begin{array}{l}\text { Similarity } \\
\text { ratio }\end{array}$ & 1 & 29 & 28 & 30 & 1 & 29 & 1 \\
\hline
\end{tabular}

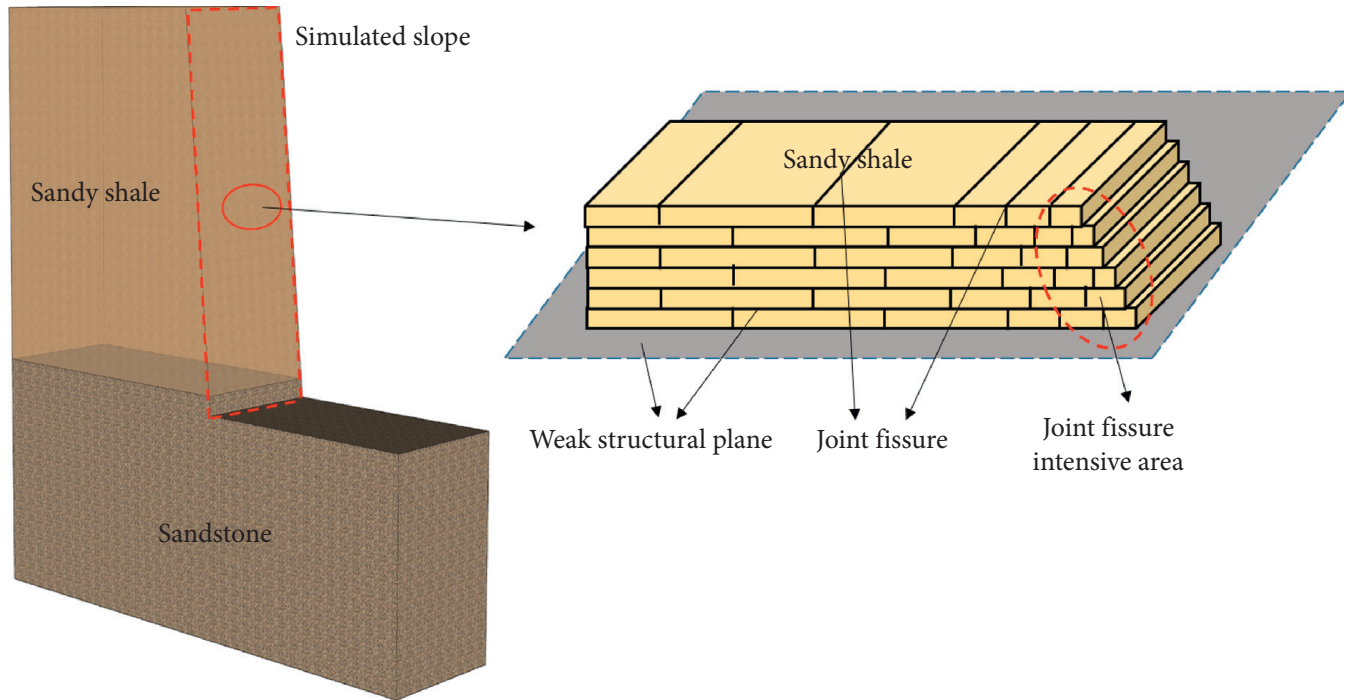

FIGURE 5: Joint fissure simulation diagram of slope model.

diameter of the sleeve pipe. When the cone and the sleeve pipe slip were relative to each other, the frictional resistance (such as the working resistance of the bolt) was generated. The inner surface of the sleeve pipe was screw thread structure, which increased friction along with the cone. When the axial external load (tension) acted in the opposite direction to the anchored end on the working bearing plate, the sleeve pipe displacement was relative to the cone, while the NPR bolt was extended as a whole.

(2) Working Principle of NPR Bolt. Figure 8 presents the NPR static stretch diagram. Its working was divided into three stages. In the elastic deformation stage, when the deformation energy of surrounding rock was low and the axial force applied on the shank rod was lower than the design constant resistance of bolt, the constant resistance device did not move. At this time, the bolt relied on the elastic deformation of the bolt body material to resist the deformation and failure of rock mass. The structural deformation stage, which, with the gradual accumulation of deformation energy of surrounding rock, the axial force applied on the bolt body was higher than or equal to the design constant resistance of the NPR bolt. The cone in the sleeve pipe slid along the inner wall of the casing; the constant resistance was furnished during the slip process, relying on the structural deformation of the constant resistance device to resist the deformation and failure of rock mass. After the bolt deformation of material and structure, the deformation of surrounding rock could be fully released, while the surrounding rock was again in a relatively stable state. In the destruction stage, the surrounding rock continued to deform, while the displacement of the NPR bolt constant resistance body continued to increase beyond its ultimate tensile length; also, the NPR bolt lost its reinforcing effect.

3.2.2. Model Bolt Design. Due to the large geometric similarity, the model NPR bolt design could only satisfy the similar scale in the length direction, while the dimension of the cross-sectional direction was satisfied as high as possible on the basis of satisfying the mechanical similarity characteristics. Therefore, the length of the designed bolt was

$$
L_{M}=\frac{L_{p}}{L_{m}}=\frac{1800}{30}=60 \mathrm{~mm},
$$

where $L_{P}$ is the geometric parameter of the prototype; $L_{m}$ is the geometric parameter of the model. The mechanical similarity ratio of anchor bolt in experimental design was

$$
C_{F}=C_{L}^{3} C_{\gamma}=30^{3} \times 1=27000,
$$




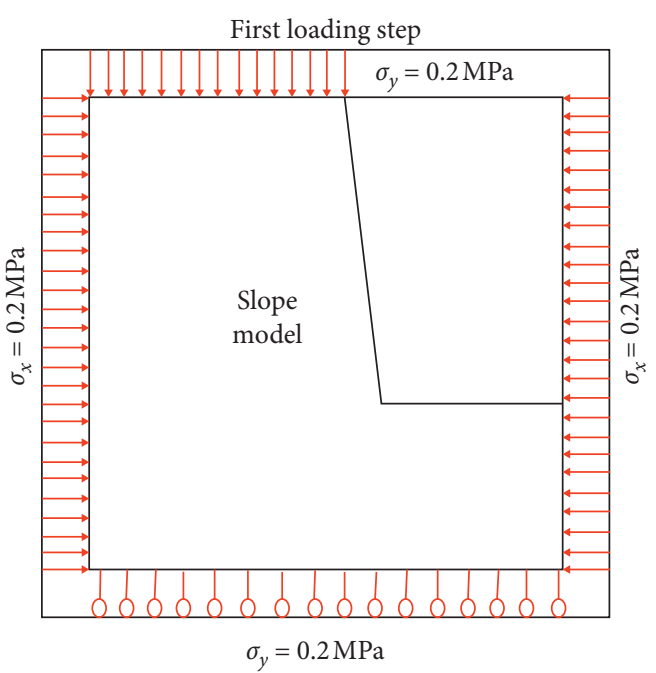

(a)

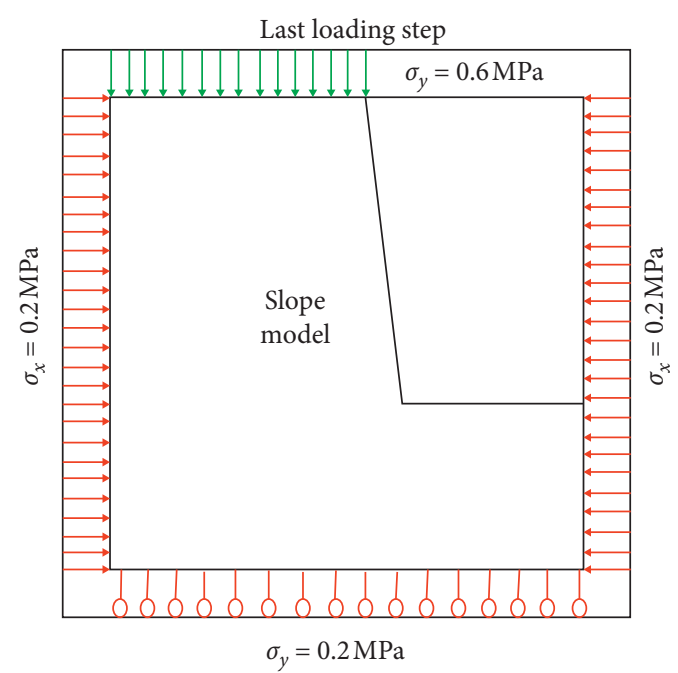

(b)

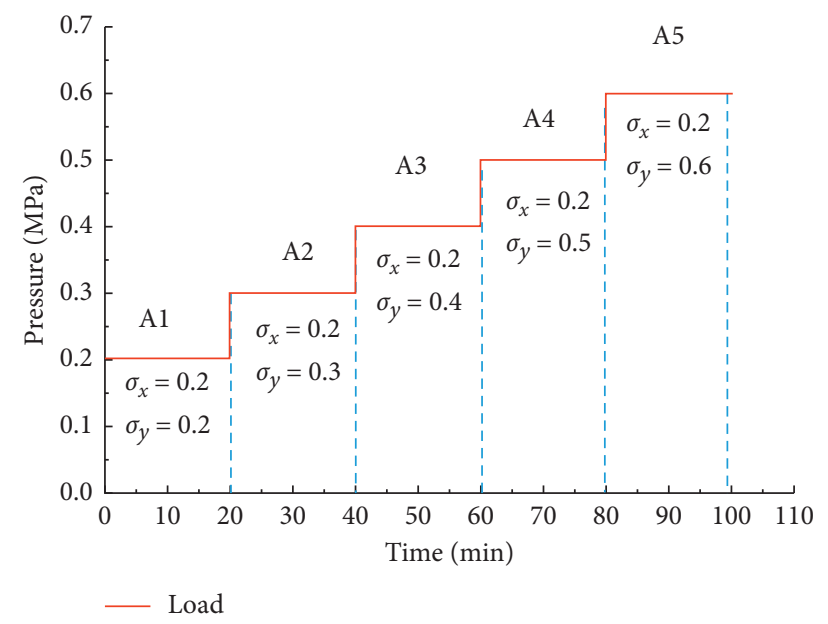

(c)

FIGURE 6: Loading path of physical model test: (a) first loading stage; (b) last loading stage; (c) hierarchical loading diagram.

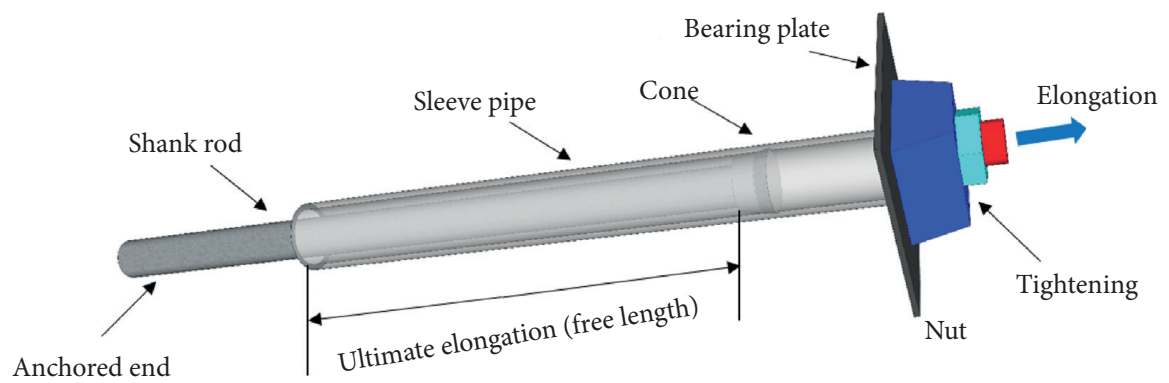

FIGURE 7: Schematic of three-dimensional view of NPR bolt.

where $C_{L}$ is geometric similarity ratio; $C_{y}$ is bulk density similarity ratio. Therefore, constant resistance could be obtained as

$$
P_{M}=\frac{P}{C_{F}}=\frac{160 \mathrm{kN}}{27000} \approx 6 \mathrm{~N},
$$

Due to the model size limitation, if the reinforcement was carried out according to the calculation results of similarity ratio, the bolt installation spacing would be too low. Finally, one bolt was determined to replace six bolts. This signified that the constant resistance of the bolt in the design model was

$$
P_{M}^{\prime}=P_{M} \times 6=6 \mathrm{~N} \times 6=36 \mathrm{~N} .
$$

The mechanical parameters of engineering-scale NPR bolts and model-scale NPR bolts are presented in Table 2 . 


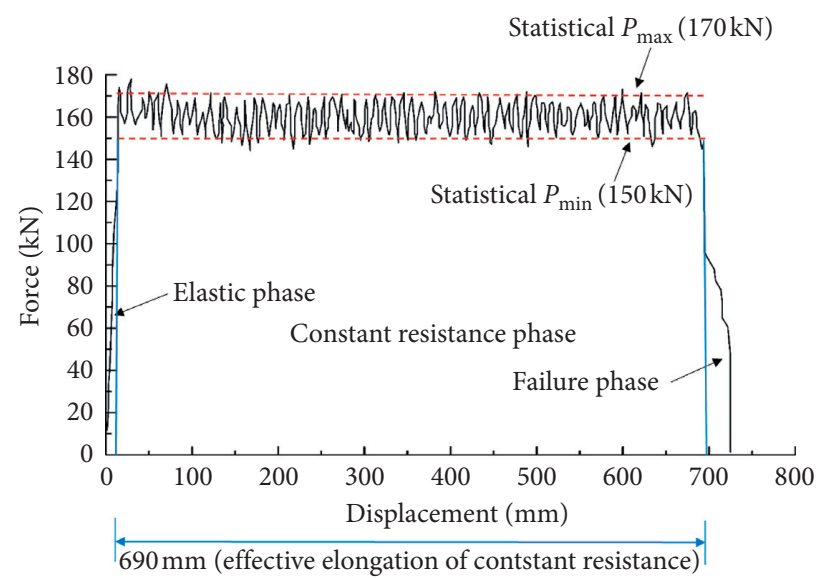

Figure 8: Static tension diagram of NPR bolt.

TABle 2: Physical and mechanical parameters of engineering-scale and model-scale bolts.

\begin{tabular}{|c|c|c|c|c|c|}
\hline Bolt type & Length (mm) & Elongation indicator $(\mathrm{mm})$ & $\begin{array}{l}\text { Maximum tensile force } \\
(\mathrm{N})\end{array}$ & $\begin{array}{l}\text { Minimum tensile force } \\
(\mathrm{N})\end{array}$ & $\begin{array}{l}\text { Average value } \\
(\mathrm{N})\end{array}$ \\
\hline Engineering-scale NPR bolts & 1800 & 700 & 17000 & 150000 & 160000 \\
\hline Model-scale NPR bolts & 135 & 56 & 43 & 33 & 37 \\
\hline
\end{tabular}

Figure 9 presents the NPR bolt model: (1) was a sleeve pipe of $8 \mathrm{~mm}$ in inner diameter, the external diameter was $10 \mathrm{~mm}$, and the length was $65 \mathrm{~mm}$; (2) was a cone of $4.8 \mathrm{~mm}$ in small end diameter and $8.1 \mathrm{~mm}$ in large end diameter. The diameter of the large end was higher than the inner diameter of the constant resistance sleeve, while a small hole mounting rod was left at the top of the cone and the cone was mounted inside the sleeve pipe to form a constant resistance device; (3) was a tightening nut, which was installed at the top of the sleeve pipe, prestressing the NPR bolt; (4) was a bearing plate to transfer prestressing force; (5) was a shank rod, for which one end was connected to the top of the cone, while the other end was anchored to the rock mass. The cone was pulled by the shank rod to produce friction in the sleeve pipe as constant resistance. The model NPR bolt was composed of these five parts. The material of the sleeve, tightening nut, and bearing plate was resin, made through 3D printing SLA (Stereo Lithography Apparatus) technology, which restored the constant resistance reinforcement characteristics of NPR bolt.

Figure 10 presents the static tension curve of the model NPR bolt. It could be observed that bolt reinforcement deformation could be divided into elastic stage, constant resistance stage, and failure stage. Tensile displacement was $2 \mathrm{~mm}$ in elastic stage and $55 \mathrm{~mm}$ in the constant resistance stage. The maximum resistance of model bolt was $43 \mathrm{~N}$, for which the minimum was $33 \mathrm{~N}$ and the average value was $37 \mathrm{~N}$, which was basically the same as the design value of model bolt.

3.2.3. Reinforcement Monitoring Design. Figure 11 presents the reinforcement layout design; a total of 8 bolts were designed to be installed in 5 rows (i.e., rows $A, B, C, D$, and $\mathrm{E})$, two bolts were installed in rows $\mathrm{A}, \mathrm{C}$, and $\mathrm{E}$, and one bolt was installed in rows $\mathrm{B}$ and $\mathrm{D}$, respectively. The pressure sensor was installed between the bearing plate and the tightening nut for whole-course pressure monitoring, while the anchored net was fixed under the bearing plate. The pressure sensor could monitor the pressure change of the bolt in real time.

Figure 12 presents the structure of anchored net; it was made of spiral iron wire. Its static tensile curve was presented in Figure 13. The iron of anchored net could bear the maximum tension of $25 \mathrm{~N}$ in the deformation stage of its own structure, while its yield strength was $190 \mathrm{~N}$. When the collapse failure occurred, the anchored net was forced to produce tensile deformation, while absorbing the instantaneous impact force generated through the collapse mass to prevent the anchored net from being destroyed; then the anchored nets were pulled up and deformed. It was extended as a whole and produced "net pocket" effect to encapsulate the falling rocks. Also, it could prevent the falling rocks causing damage.

\section{Analysis of Experimental Results}

4.1. Failure Process Analysis. Figure 14 presents the stress record of $\mathrm{B} 1$ and $\mathrm{C} 1$ pressure sensors for the entire loading process of the model slope. Due to the pressure generated after prestressing, it was necessary to reset the pressure sensor to zero so as to observe the pressure change during the test.

According to the stress change of the monitoring curve, the reinforcement could be divided into three stages: the elastic stage, the constant resistance stage, and the failure stage. In the elastic stage, no large deformation exists in the surrounding rock of the slope and the axial force applied on the bolt body was lower than the constant resistance of the 


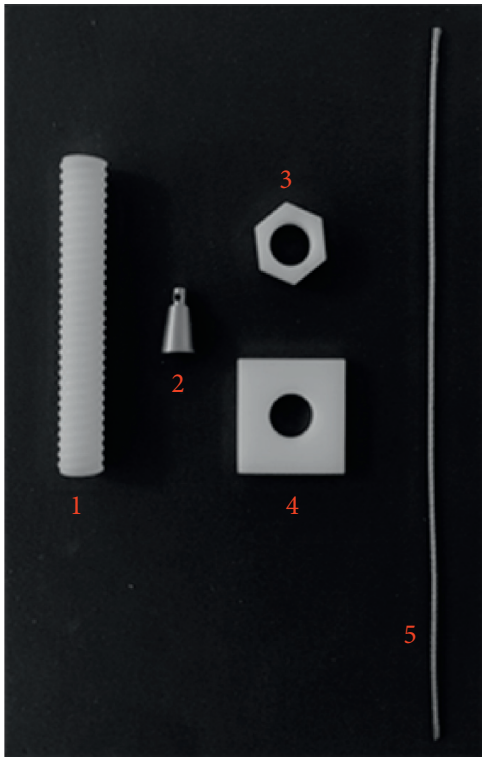

(a)

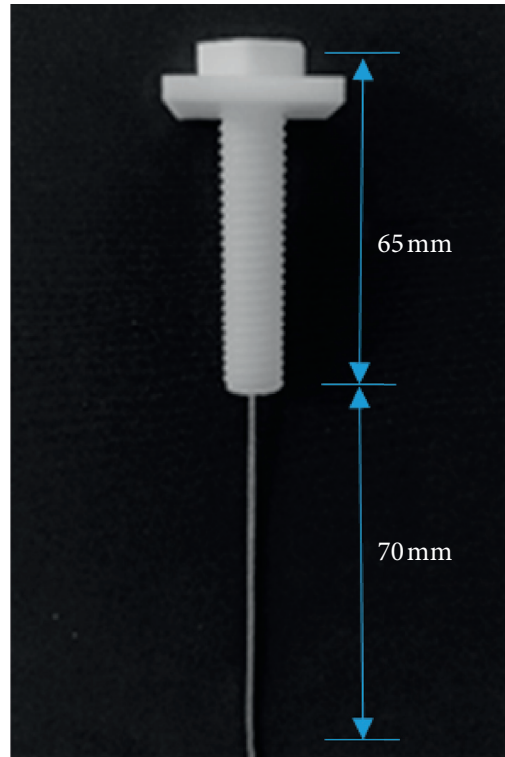

(b)

FIGURE 9: NPR bolt model: (a) bolt components; (b) NPR bolt assembled.

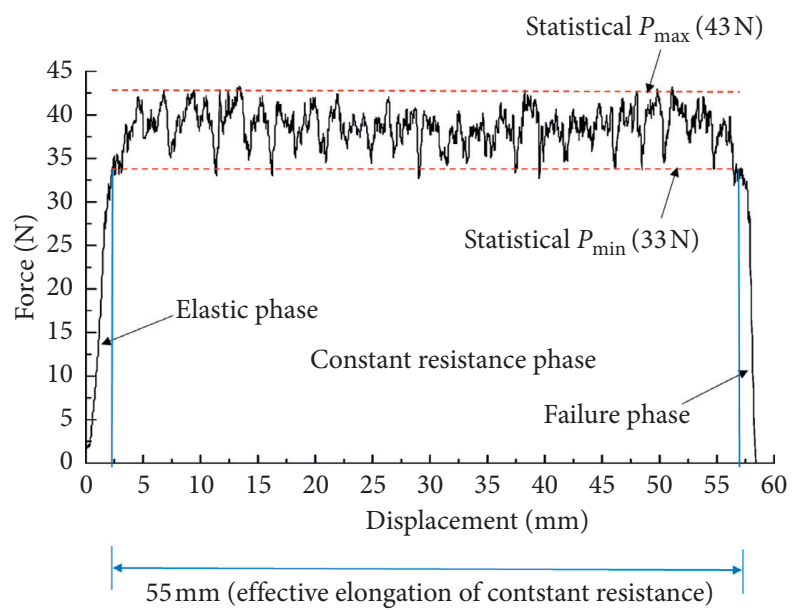

FIgURE 10: Model NPR bolt static tension curve.

model NPR bolt. The constant resistance device did not slip. The bolt relied on the elastic deformation of the bolt body material to resist the deformation and failure of the rock mass, while the pressure monitoring curve continued to decline. In the constant resistance stage, with the accumulation of deformation energy of the surrounding rock of the slope, the surrounding rock displaced, while the axial force applied on the bolt body was higher than the constant resistance of the bolt. The constant resistance body in the constant resistance device slid. After the deformation of the material and structure of the bolt, the surrounding rock was again in a relatively stable state, while the pressure monitoring curve remained relatively stable for a period of time subsequently to fluctuation. In the failure stage, as the surrounding rock continued to deform beyond its ultimate tensile length, the anchor broke and the pressure monitoring curve dropped sharply to zero. According to the collapse process of the experimental model, combined with the stress of the monitoring curve, the pressure monitoring curve was divided into five processes, namely, $\mathrm{OA}, \mathrm{AB}, \mathrm{BC}, \mathrm{CD}$, and DE.

The curves $\mathrm{AB}$ and $\mathrm{BC}$ correspond to the elastic phase of the model NPR bolt. The pressure curve continued to descend and then remained relatively stable, but there was no significant fluctuation, indicating that the axial force applied on the bolt was lower than the constant resistance of the model NPR bolt. The constant resistance device did not slip. The bolt relied on the elastic deformation of the bolt material to resist the deformation and collapse of the rock mass. The curves $\mathrm{CD}$ and DE correspond to the constant resistance phase of the bolt. The pressure curve began to fluctuate following a sharp drop and then fluctuated sharply after 


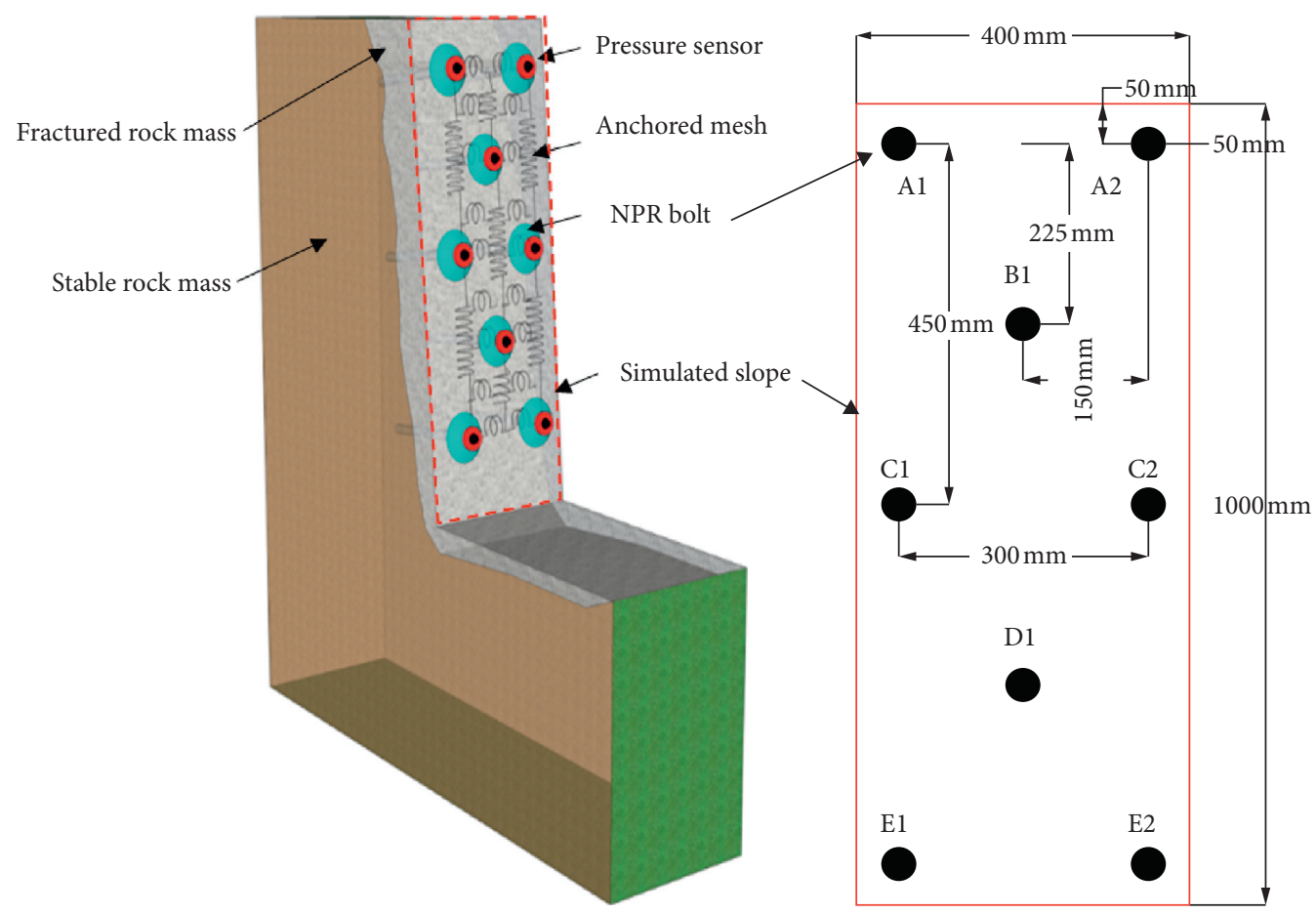

FIGURE 11: NPR bolt support system layout.

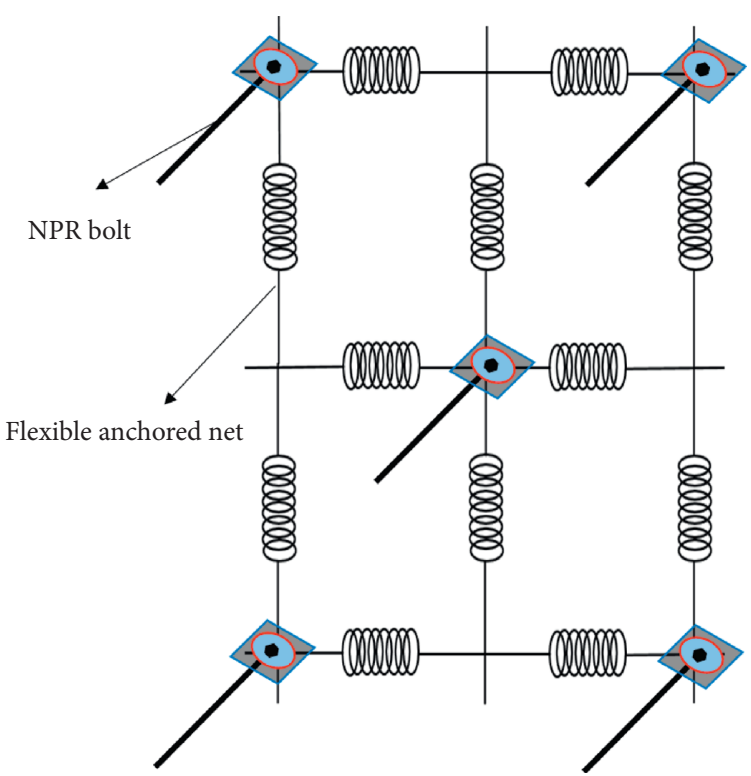

FIgURE 12: Anchored net structure support system layout.

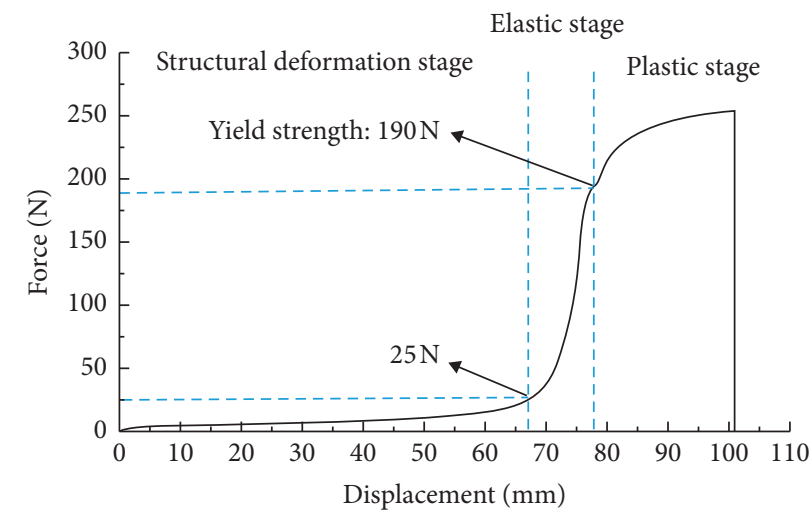

FIgURE 13: Static tension curve of the single anchored net. 


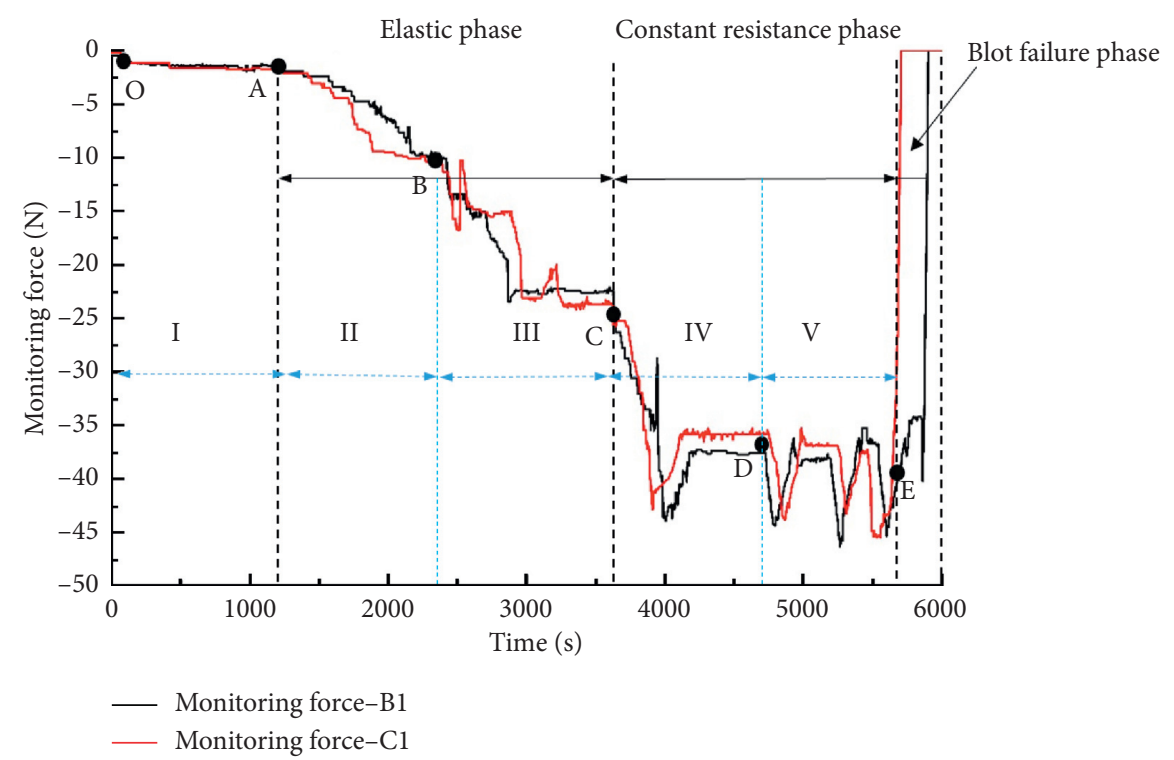

FIGURE 14: Stress record of the whole test process.

remaining relatively stable for a period of time. It indicated that the cone had slid and the bolt had structural deformation. After the curve point E, the bolt removal stage was corresponding. The pressure curve rises sharply to zero. It presented that the bolt reached its ultimate tensile length; the bolt was broken and lost its function.

Figure 15(a) presents the model picture of compaction stage. The horizontal pressure and the vertical pressure were applied to the model, corresponding to the OA phase of the stress record. At this stage, the model had no apparent change. Small cracks existed in the middle of each layer of the unit plate during the model building stage. When the slope model was pressurized as a whole, the interlayer cracks were gradually compacted and the model became an entity. The record of the section OA presents that the pressure was unchanged basically; this indicated that the slope was stable.

Figure 15(b) presents the model picture of fracture generation stage. The horizontal pressure and the vertical pressure were applied to the model, corresponding to $\mathrm{AB}$ section of stress record. At this stage, many microcracks occurred in the model. As presented in Figure 15(b) (i), the vertical microcracks were generated near the slope surface, such as in the red solid line marking position. Many cracks occurred near the slope in the lower part of the model of $1 \mathrm{~mm}$ in width. As presented in Figure 15(b) (ii), bulges and cracks existed in the middle and lower parts of the slope, along with small cracks and breakage in other parts, without deformation in the anchored net. The record of section $A B$ presented the continuous increase of pressure. It means that the internal stress of rock mass changed, which was the first stage of slope collapse monitoring.

Figure 15(c) presents the model picture of fracture propagation stage. The horizontal pressure and vertical pressure were applied to the model, corresponding to the $\mathrm{BC}$ section of the stress record. As presented in Figure 15(c) (i), the cracks in the upper part of the model section near the slope surface extended to the deep part of the slope; the maximum width of the cracks was $7 \mathrm{~mm}$, while the width of the cracks in the middle part was $2 \mathrm{~mm}$. Two circular protrusions occurred on the upper surface of the model section; the diameter was 1 to $2 \mathrm{~cm}$. As presented in Figure 15(c) (ii), the upper part of the slope was severely damaged, with the surface spalling within a large area. A low amount of collapse blocks was wrapped by the anchored net, while the anchored net was deformed by punching. A high amount of cracks occurred in the middle and lower parts, while a low amount of surface spalls occurred. From record of section BC, it could be observed that the increase remained stable following a sharp drop. It indicates that the internal stress of rock mass continued to increase, which constituted the second stage of slope collapse monitoring.

Figure 15(d) presents the model picture of local collapse stage. The horizontal pressure and the vertical pressure were applied to the model, corresponding to the CD section of the stress record. At this stage, the upper part of the model collapsed and the entire model was unstable. As presented in Figure 15(d) (i), the cracks in the upper part of the model section near the slope extended to the middle; the widest part of the cracks was $10 \mathrm{~mm}$. A large number of cracks in the upper part of the model had a width of 1-5 mm. There are 5 circular bulges with a diameter of $1-5 \mathrm{~mm}$ in the upper part of the slope. As presented in Figure 15(d) (ii), the upper and middle parts of the slope collapsed, resulting in large pieces of collapse peeling off and wrapping by anchor mesh, leading to severe deformation of the anchored net. The collapse in the lower part of the model was lighter than that in the upper part; the surface spalling within a large area and the anchored net produced a low amount of deformation. The record of section CD presents that the pressure curve rose slightly after a sharp drop and then remained stable; it means that the NPR bolt began to produce structural deformation.

Figure 15(e) presents the model picture of the entire collapse stage. The horizontal pressure and vertical pressure 

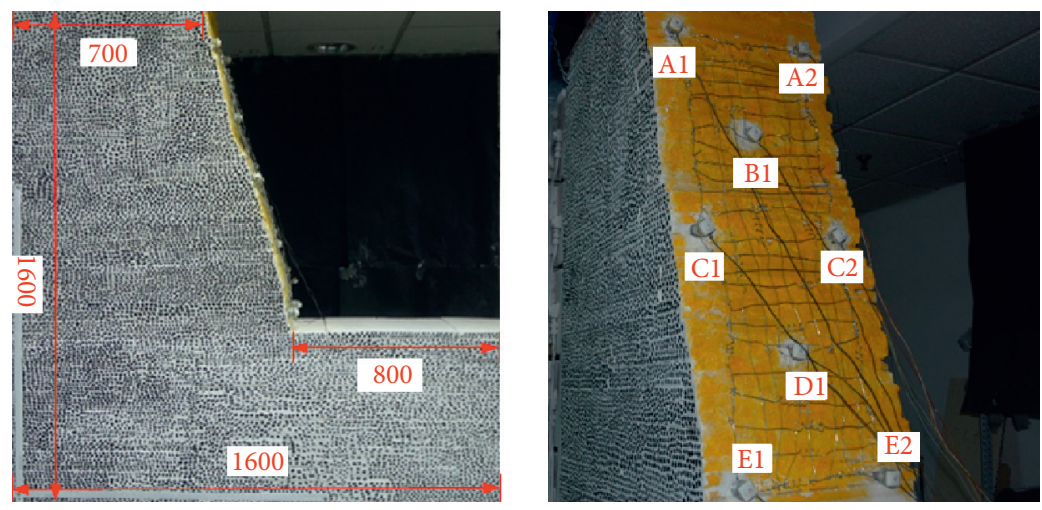

(a)
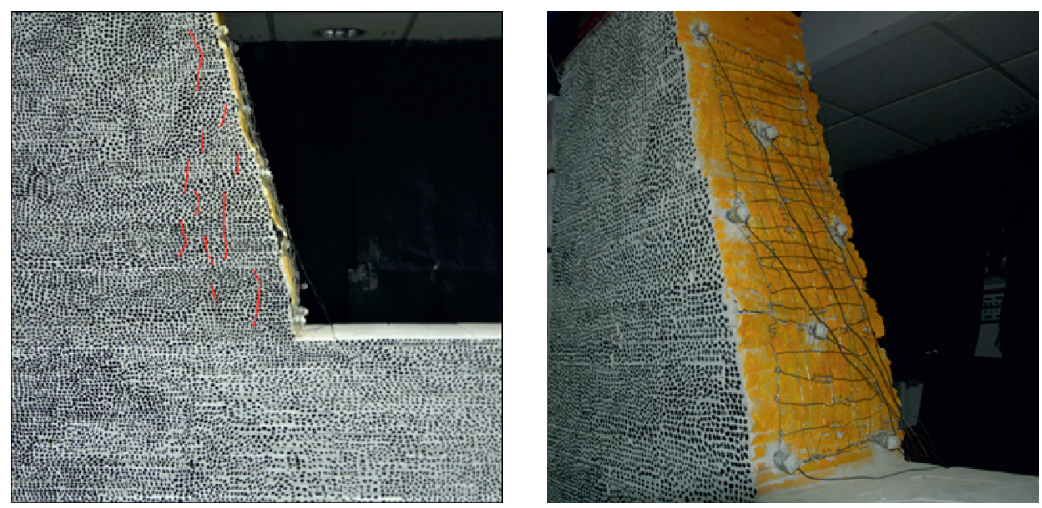

(b)
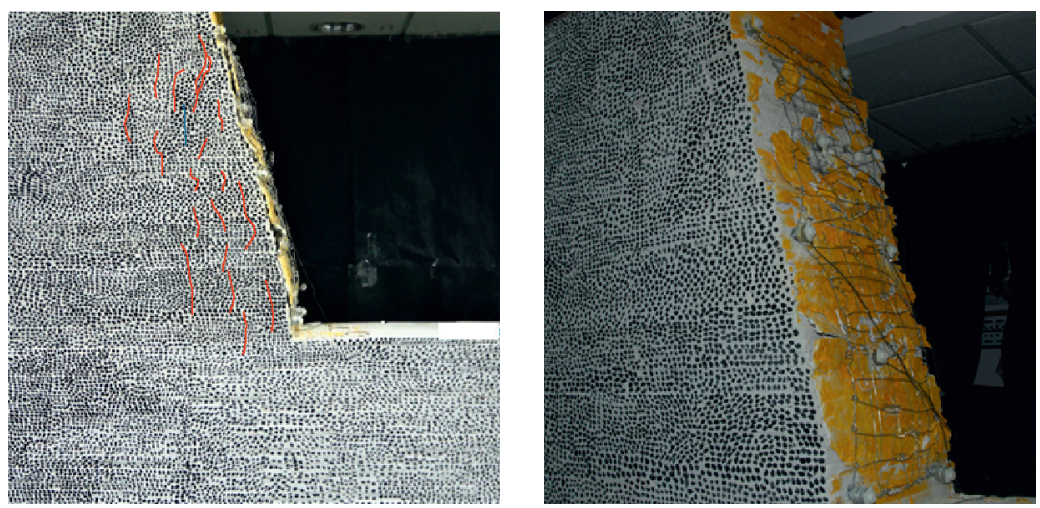

(c)
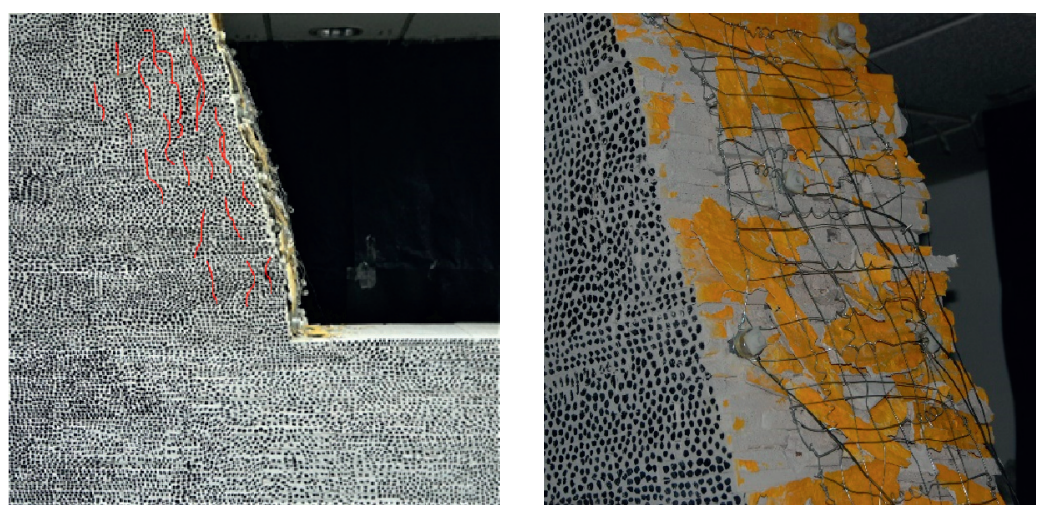

(d)

Figure 15: Continued. 

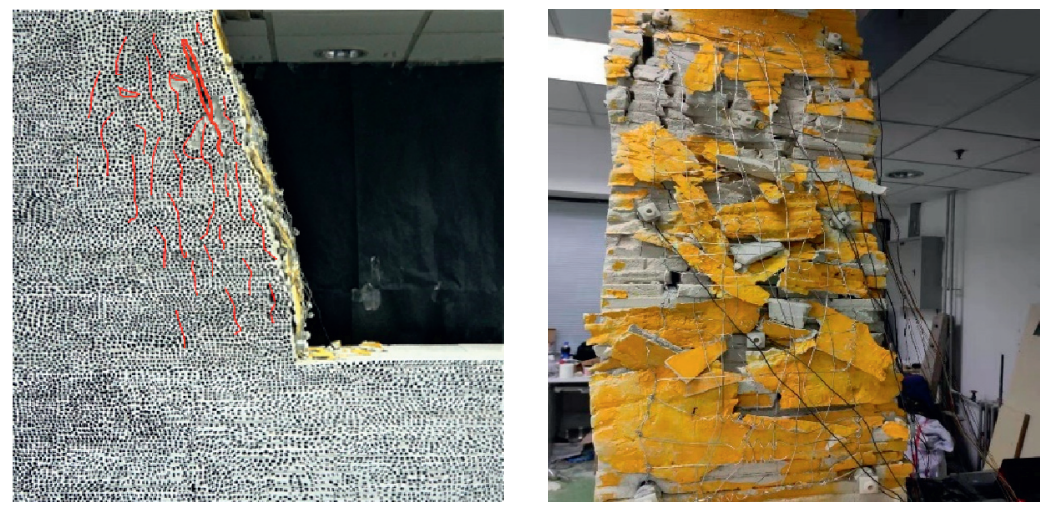

(e)

FIGURE 15: . Photograph of model collapse process: (a) compaction stage: (i) lateral view and (ii) side view; (b) fracture generation stage: (i) lateral view and (ii) side view; (c) fracture propagation stage: (i) lateral view and (ii) side view; (d) local collapse stage: (i) lateral view and (ii) side view; (e) entire collapse stage: (i) lateral view and (ii) side view.

were applied to the model, corresponding to the DE section of the stress record. At this stage, the model occurs the large area collapse. As presented in Figure 15(e) (i), the cracks in the upper part of the model section extended around the slope with a maximum crack width of $15 \mathrm{~mm}$. Also, a high amount of cracks occurred in the middle and upper parts of $1 \mathrm{~mm}$ to $5 \mathrm{~mm}$ in width, while a low amount of spalling occurred on the upper surface. As presented in Figure 15(e) (ii), the entire slope was collapsed; in addition, serious deformation occurred on the slope, and a large amount of collapse spalling was wrapped by the anchored net. This led to severe deformation of the anchored net. It could be seen from the $\mathrm{CD}$ segment record that the pressure fluctuates with a high frequency; it presented that the NPR bolt continued to produce structural deformation.

\subsection{Digital Speckle}

4.2.1. Principle. In this model experiment, the MTI-2D digital image measurement system was utilized to quantify the full-field displacement [33-35]. This system was also called noncontact strain measurement and parameter reverse analysis system. It was composed of MTI-2D twodimensional measurement and simulation optimization analysis software, AVT-CCD industrial camera, and lighting system (halogen lamp or LED), along with fixture and calibration board. The two-dimensional measurement and simulation optimization analysis software constituted the postprocessing software of the system, used to process the acquired image information. The image acquisition control software was connected to the industrial camera through a computer device to perform real-time image acquisition on the experimental target. The industrial camera had a maximum resolution of 5 million pixels and a frequency of $\geq 30 \mathrm{~Hz}$. The displacement pixel accuracy measured by the system was $0.001-0.01$, the displacement resolution was $0.1 \mu \mathrm{m}$, and the strain resolution was $20-50 \mu \varepsilon$, while the strain measurement range was $0.005 \%-$ $2000 \%$
Prior to experimentation, the speckles were made on the model section. The entire speckle pattern had high contrast, high anisotropy, and nonrepetition [36]. The basic principle of the system was to use the scattered spots randomly distributed on the surface of the model as the information carrier. Contrast analysis of the speckle pattern provided information, such as the displacement field.

The center point coordinates of a surface of an object were let to be $P(x, y)$ and any point of $Q\left(x_{i}, y_{i}\right)$ nearby. When the object was deformed, the corresponding coordinates of two points were $P^{\prime}\left(x_{0}^{\prime}, y_{0}^{\prime}\right)$ and $Q^{\prime}\left(x_{i}^{\prime}, y_{i}^{\prime}\right)$.

$P^{\prime}$ and $P$ had the following relationships:

$$
\begin{aligned}
& x_{0}^{\prime}=x_{0}+\mu, \\
& y_{0}^{\prime}=y_{0}+v .
\end{aligned}
$$

$Q$ and $Q^{\prime}$ had the following relationships:

$$
\begin{aligned}
& x_{i}^{\prime}=x_{i}+\mu_{\mathrm{Q}}, \\
& y_{i}^{\prime}=y_{i}+v_{\mathrm{Q}},
\end{aligned}
$$

where $\mu$ and $v$ represent the displacement components of point $P$ on the $x$ - and $y$-axes, respectively; $\mu_{\mathrm{Q}}$ and $v_{Q}$ represent the displacement components of point $Q$ on the $x$ and $y$-axes, respectively.

Let the gray scale of point $p$ prior to and following deformation be

$$
\begin{aligned}
f(Q) & =f\left(x_{i} y_{i}\right), \\
g\left(Q^{\prime}\right) & =g\left(x_{i}^{\prime}, y_{i}^{\prime}\right) .
\end{aligned}
$$

It could be concluded that

$$
\begin{aligned}
\mu_{\mathrm{Q}} & =\left(\mu+\mu_{x} \Delta x+\mu_{y} \Delta y\right), \\
v_{\mathrm{Q}} & =\left(v+v_{x} \Delta x+v_{y} \Delta y\right), \\
\Delta x & =\left(x_{i}-x_{0}\right), \\
\Delta y & =\left(y_{i}-y_{0}\right) .
\end{aligned}
$$

Among these, $f$ represents the gray scale function of the image before deformation and $g$ represents the gray scale 
function of the image after deformation. $\mu, \mu_{x}, \mu_{y}, v, v_{x}, v_{y}$ are displacement vectors.

In order to determine the displacement correspondence before and after deformation, $C(f, g)$ is introduced to determine the degree of similarity of the images before and after the displacement as

$$
C(f, g)=C\left(x_{i}, y_{i}, x_{i}^{\prime}, y_{i}^{\prime}\right)=C(P) .
$$

From the above equation, it could be observed that $C(f, g)$ is a function of $P$ and its minimum value was found as

$$
\frac{\partial C}{\partial P}=0 .
$$

4.2.2. Displacement Nephogram Analysis. Figure 16(a) presents the displacement nephogram of the model compaction stage, in which the direction of horizontal displacement was the same as that of the $x$-axis. As presented in Figure 16(a) (i), the entire model produced low displacement, while the displacement of the top part of the model was apparent. The displacement presented a decreasing trend from the upper part to the middle part of the model, while the displacement of the lower part had no apparent difference. As presented in Figure 16(a) (ii), no apparent difference existed in the displacement. This indicated that the model had reached the compact state. The maximum displacement of the top part of the model was $1.9 \mathrm{~mm}$ and the displacement of other areas was $1.3 \mathrm{~mm}$.

Figure 16(b) presents the displacement nephogram of the model fracture generation stage. As presented in Figure 16(b) (i), the horizontal displacement of the model increased significantly, while the displacement from the right side (near the slope) to the left side of the model presented a decreasing trend, while the displacement change region also presented a decreasing trend. As presented in Figure 16(b) (ii), there was a gradual increase of displacement in the central region, while it decreased in the upward and downward directions. The displacement of the middle position of the model was $6.2 \mathrm{~mm}$.

Figure 16(c) presents the displacement nephogram of the model fracture propagation stage. As presented in Figure 16(b) (i), the displacement trend changed highly and the maximum displacement region shifted to the upper part of the model compared to the fracture generation stage, and the horizontal displacement significantly increased. The displacement variation of nephogram was divided into four grades, while the displacement gradually decreased from top to bottom and the displacement increment of the upper part of the model near the slope surface was the highest. As presented in Figure 16(c) (ii), the trend of displacement had no major change in the nephogram compared to Figure 16(b) (i). The displacement growth area of the upper part of the model expanded downwards, especially on the side close to the slope, where the growth was faster and the displacement could be up to $30 \mathrm{~mm}$.

Figure 16(d) presents the displacement nephogram of the partial collapse stage of the mode. As presented in
Figure 16(d) (i), the trend of displacement change was lower compared to the fracture propagation stage. As presented in Figure 16(d) (ii), the displacement of the upper part of the model near the slope increased rapidly, while the growth region was extended along the slope to the middle. No apparent change existed in the displacement of the lower part of the model or the upper part of model slope, while the displacement of the model reached $32 \mathrm{~mm}$.

Figure 16(e) presents the displacement nephogram of the overall collapse stage of the model. As presented in Figure 16(e) (i), the trend of displacement change in this stage was lower compared to the local collapse stage, while the displacement change region was mainly concentrated on the upper part of the model near the slope, diffusing outwards. As presented in Figure 16(e) (ii), the horizontal displacement of the model increased slowly, while the area of displacement growth expanded downwards. The maximum horizontal displacement of the upper and middle parts near the slope was $41 \mathrm{~mm}$.

Derived from the displacement cloud map during the model experiment, the horizontal displacement was mainly concentrated on the upper part of the model near the side of the slope. The displacement growth area extends downwards along the side slope, gradually decreasing from top to bottom. The maximum displacement region extended downwards along the slope and the horizontal displacement of surrounding rock reached $41 \mathrm{~mm}$. The maximum increase of displacement was in the fracture propagation stage, but the surrounding rock did not collapse in an instant. In the stage of local collapse and entire collapse, the displacement increased slowly until the overall collapse of the slope.

4.2.3. Displacement Analysis of Monitoring Points. As presented in Figure 17, column A and column B monitoring points were taken parallel to the slope direction in the slope model; the horizontal distance between column $\mathrm{A}$ and the slope was $5 \mathrm{~cm}$, while column $B$ was $15 \mathrm{~cm}$. The distance between points $A 1$ and $B 1$ and the top of the slope was $10 \mathrm{~cm}$, and the vertical distance between each monitoring point was $25 \mathrm{~cm}$. The monitoring points were selected to analyze the change rule of horizontal displacement.

The horizontal axis coordinates of the following displacement curves represented pictures of different states corresponding to different moments taken through the speckle system during the entire experiment. Stages I, II, III, IV, and V in the displacement curves represented the model compaction stage, the fracture generation stage, the fracture expansion stage, the partial collapse stage, and the overall collapse stage, respectively.

In Figure 18, it could be observed that the horizontal displacement trends of column A and column B were roughly the same. The horizontal displacement curve of each monitoring point increased apparently, but the displacements of measuring points of A5 and B5 were unchanged. The increasing range of displacement of each monitoring point (except point A2) grew gradually from the bottom to top, especially for monitoring point A2. The fracture expansion stage had a high influence on the 

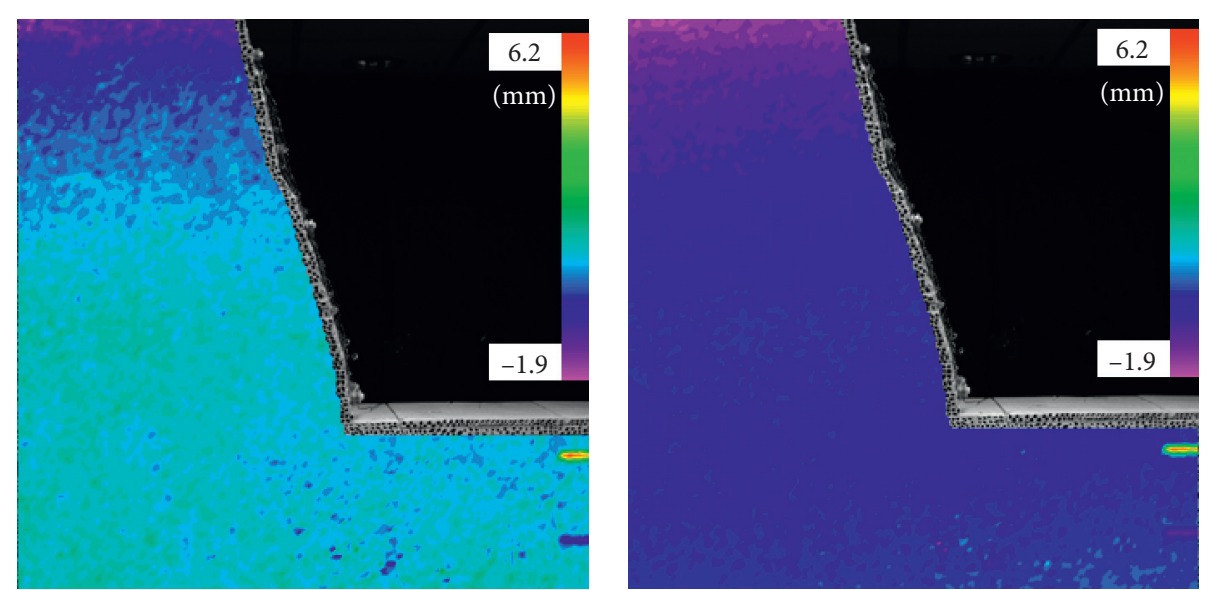

(a)
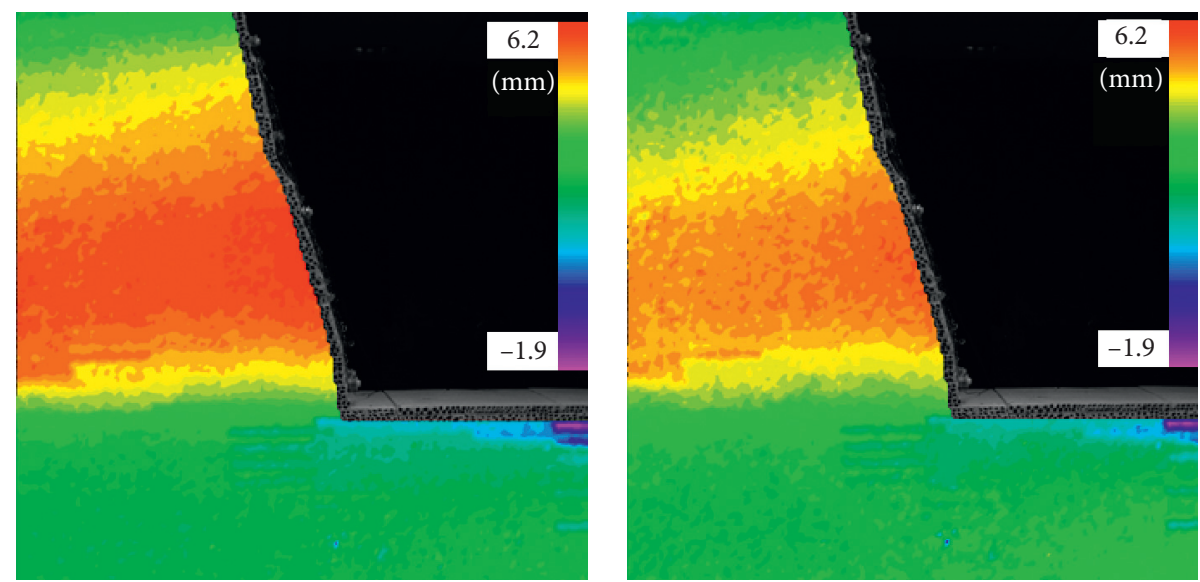

(b)
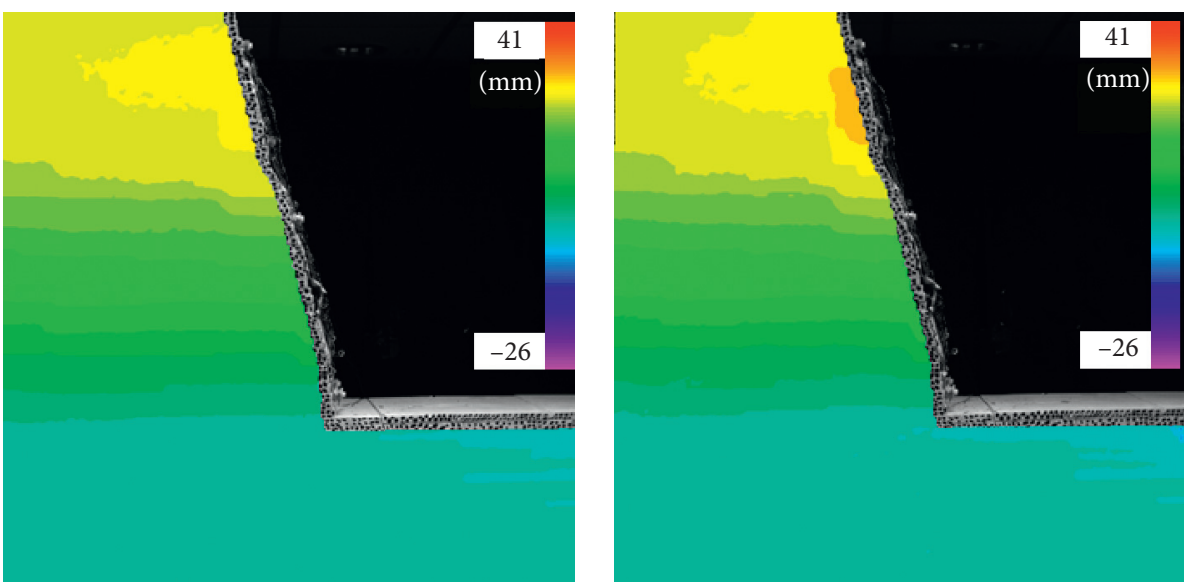

(c)

Figure 16: Continued. 

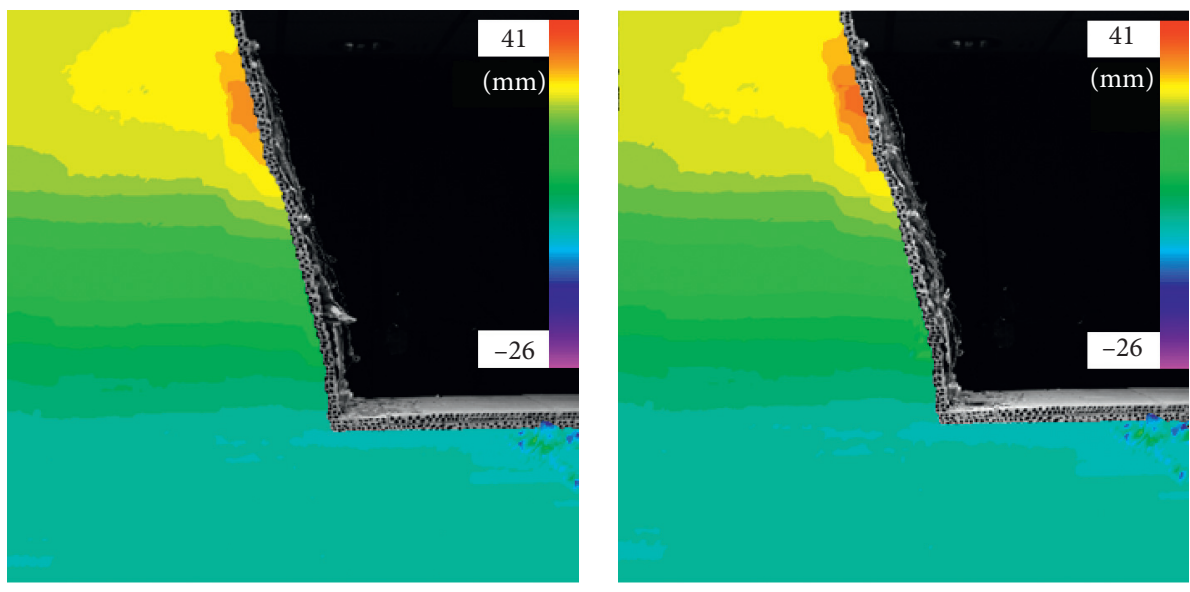

(d)
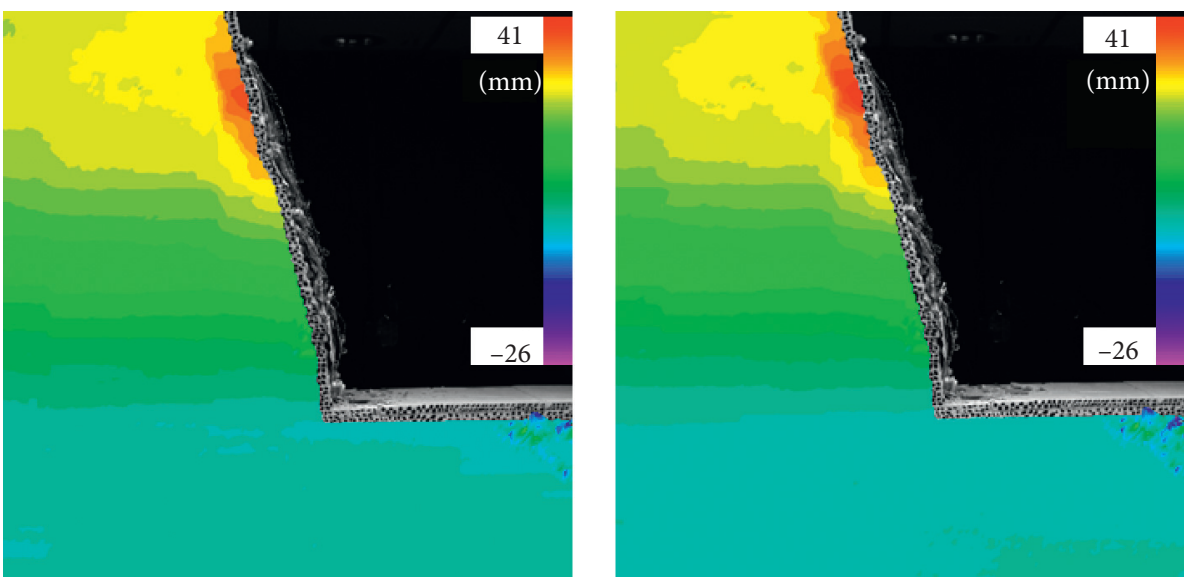

(e)

FIGURE 16: Displacement nephogram of slope model: (a) compaction stage: (i) prior to load application and (ii) after loading; (b) fracture generation stage: (i) prior to load application and (ii) after loading; (c) fracture propagation stage: (i) prior to load application and (ii) after loading; (d) local collapse stage: (i) prior to load application and (ii) after loading; (e) entire collapse stage: (i) prior to load application and (ii) after loading.

horizontal displacement of the model, but, after this stage, the displacement was raised slightly with the loading path. The displacement of the monitoring points A1, A2, B1, and B2 were higher than others; this indicated that the collapse was mainly concentrated in the middle and upper parts of the slope. The horizontal displacement of column A was larger than that of column B as a whole; this indicated that the closer to the slope area, the more serious the rock mass collapse. The maximum horizontal displacement of column A was $35 \mathrm{~mm}$, while that of column B was $28 \mathrm{~mm}$.

\section{Discussion}

As an important research method, the physical model test has some difficulties and limitations in quantitative research, but this method can directly reflect the real process of slope collapse under support conditions. The physical model is mainly adopted with simplified geological conditions. Although the physical model presupposes the surrounding rock joints, it is unable to simulate the joints widely distributed in the rock mass. The joint setting in the physical model will lead to some differences between the test results and the field observation results, which is one of the challenges faced by the current physical model test methods. In order to solve this problem, the model block made of similar materials is used to establish the test model, and the interface between the model blocks is used to simulate the nodes.

The model test phenomenon should well reflect the deformation of slope under the support of NPR bolt system. The failure characteristics of the slope agree well with the displacement monitoring results. Through the monitoring of NPR anchor pressure, the supporting effect is verified, especially the change rule of pressure record, which has certain reference value for rock slope collapse monitoring. The experiment reproduces the collapse process of rock slope and reveals the supporting effect of NPR anchor. In this paper, the physical model test method is proposed to provide an effective method for the study of rock slope collapse support and monitoring. 


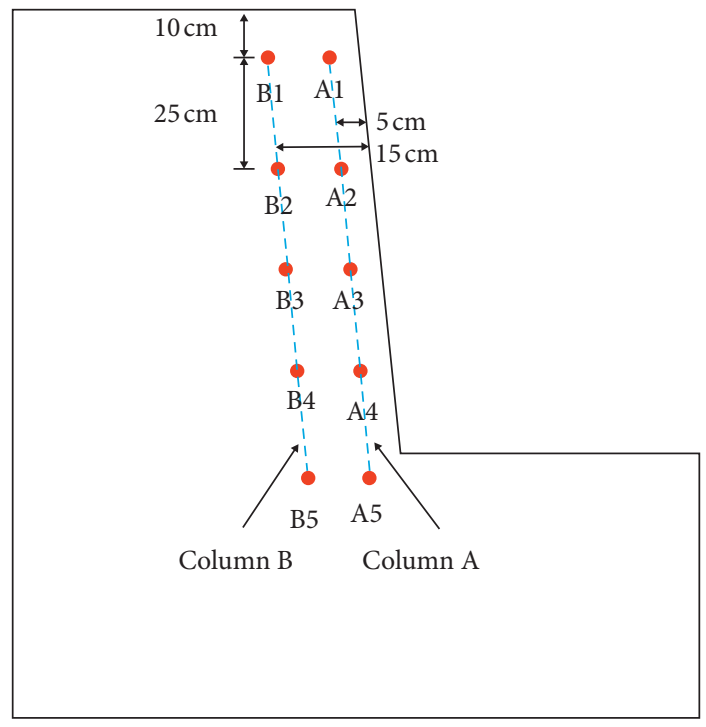

Figure 17: Displacement measuring points layout.

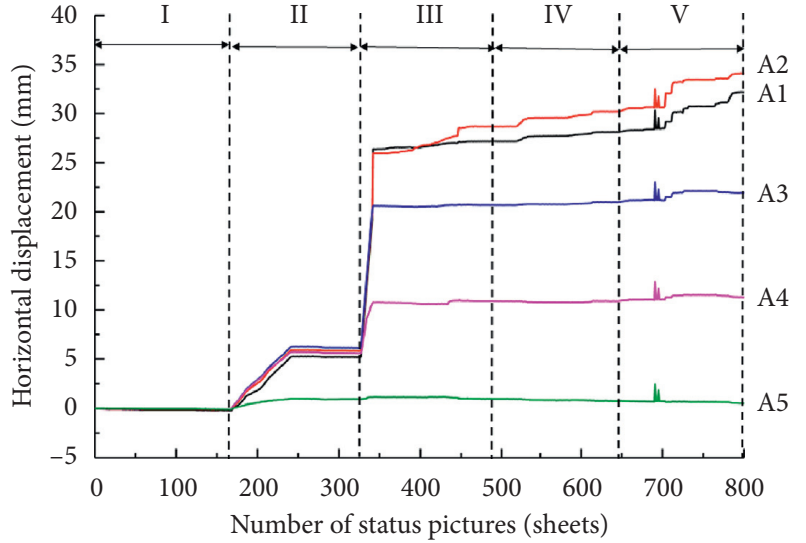

(a)

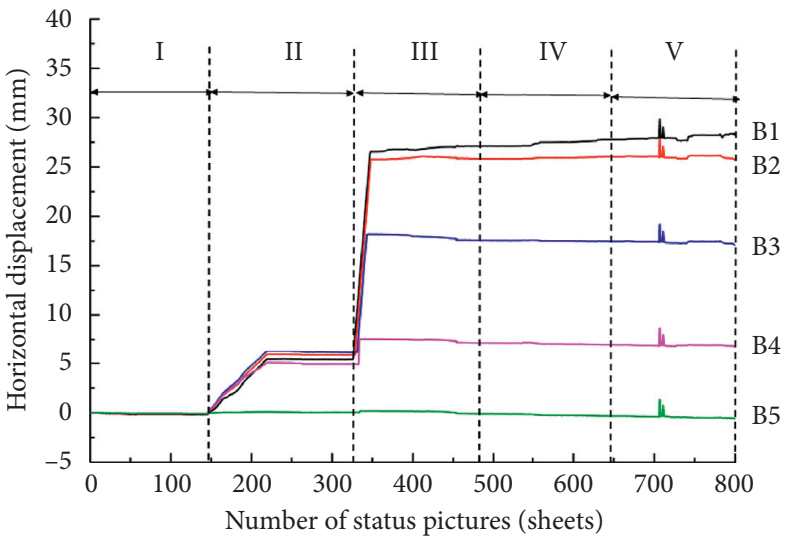

(b)

FIGURE 18: Horizontal displacement curves of displacement measuring points: (a) A1-A5 measuring points; (b) B1-B5 measuring points.

\section{Conclusions}

Physical model tests and pressure sensor and displacement nephogram analyses were carried out to investigate the effects of NPR bolt system, characteristics of collapse, and monitoring of rock slope. Based on the test and the numerical results, the following conclusions may be drawn:

(1) According to the analysis of the slope failure characteristics, the slope model collapse can be divided into four distinct stages: fracture generation stage, fracture propagation stage, local collapse stage, and overall collapse stage.

(2) The displacement nephogram of the slope and the displacement change trend of the monitoring points show that the displacement increases the most in the fracture propagation stage, but the surrounding rock did not collapse in an instant. Then, the displacement increased slowly until the whole slope collapsed. It indicated that the NPR bolt had a constant resistance effect after being subjected to the instantaneous impact force, effectively preventing the instantaneous overall collapse of the surrounding rock; that realized the stable reinforcement of surrounding rock and highly reduced the potential safety hazards of rock slope collapse. Flexible anchored net absorbed the instantaneous impact force of the falling rocks, while wrapping it to prevent falling.

(3) From the comprehensive analysis of slope failure characteristics and stress records, it could be concluded that the change of pressure curve presented apparent regularity in the entire process of slope collapse and reflected the change state of the internal force of surrounding rock. The curve in section $A B$ was decreased apparently. It means that the internal stress of rock mass changed, which was the first stage of slope collapse monitoring. The curve of section BC 
presents declined sharping and then maintains a transitory stable stage. This was the second stage of collapse monitoring; this monitoring stage of slope was particularly important; this indicated that the slope was imminent collapse.

(4) Through the comprehensive analysis of model test, the new support system has good support effect on the deformation and failure of rock slope with joints and has the function of slope monitoring, which can catch the stress change of surrounding rock timely and without delay, and has high monitoring accuracy for the test slope, thus providing a theoretical basis for the support and monitoring of other similar rock slopes.

\section{Data Availability}

All data are available and have been explained in this article; readers can access the data supporting the conclusions of the study.

\section{Disclosure}

The funders had no role in the design of the study; in the collection, analyses, or interpretation of data; in the writing of the manuscript; or in the decision to publish the results.

\section{Conflicts of Interest}

The authors declare that they have no conflicts of interest.

\section{Authors' Contributions}

Zhigang Tao and Daoyong Zhu conceptualized the study; Zhigang Tao contributed to methodology; Tongxing Zhang and Weili Gong provided software; Manchao He contributed to formal analysis; Daoyong Zhu was responsible for data curation; Tongxing Zhang wrote and prepared the original draft; Zhigang Tao and Tongxing Zhang wrote, reviewed, and edited the manuscript.

\section{Acknowledgments}

This study was supported by the Zhejiang Province Key R\&D Projects (no. 2019C03104) and the Fundamental Research Funds for the Central Universities, SCUT (no. 2015QB02).

\section{References}

[1] N. Wu, Z. Z. Liang, J. R. Zhou, Y. Z. Zhang, Y. Q. Hu, and X. H. Li, "Energy evolution characteristics of coal specimens with preformed holes under uniaxial compression," Geomechanics and Engineering, vol. 20, no. 1, pp. 55-66, 2020.

[2] G. Feng, Y. Kang, and X. C. Wang, "Investigation on the failure characteristics and fracture classification of shale under Brazilian test conditions," Rock Mechanics and Rock Engineering, pp. 1-16, 2020.

[3] Z. Qin, H. L. Fu, and X. X. Chen, "A study on altered granite meso-damage mechanisms due to water invasion-water loss cycles," Environmental Earth Sciences, vol. 78, no. 14, p. 428, 2019.
[4] N. Jiang, C. X. Wang, H. Y. Pan, D. W. Yin, and J. B. Ma, "Modeling study on the influence of the strip filling mining sequence on mining-induced failure," Energy Science \& Engineering, pp. 1-17, 2020.

[5] A. Li, Y. Liu, F. Dai, K. Liu, and M. D. Wei, "Continuum analysis of the structurally controlled displacements for largescale underground caverns in bedded rock masses," Tunneling and Underground Space Technology, vol. 97, Article ID 103288, 2020.

[6] D. Z. Ren, D. S. Zhou, D. K. Liu, F. Dong, S. Ma, and H. Huang, "Formation mechanism of the upper triassic Yanchang formation tight sandstone reservoir in Ordos basin-take Chang 6 reservoir in Jiyuan oil field as an example," Journal of Petroleum Science and Engineering, vol. 178, pp. 497-505, 2019.

[7] S. J. Chen, D. W. Yin, N. Jiang, F. Wang, and Z. Zhao, "Mechanical properties of oil shale-coal composite samples," International Journal of Rock Mechanics and Mining Sciences, vol. 123, Article ID 104120, 2019.

[8] J. Wang, P. Qiu, J. Ning, L. Zhuang, and S. Yang, "A numerical study of the mining-induced energy redistribution in a coal seam adjacent to an extracted coal panel during longwall face mining: a case study," Energy Science \& Engineering, vol. 8, no. 3, pp. 817-835, 2020.

[9] J. Wang, J. G. Ning, P. Q. Qiu, S. Yang, and H. F. Shang, "Microseismic monitoring and its precursory parameter of hard roof collapse in longwall faces: a case study," Geomechanics and Engineering, vol. 17, no. 4, pp. 375-383, 2019.

[10] N. Zhang, W. Liu, Y. Zhang, P. Shan, and X. Shi, "Microscopic pore structure of surrounding rock for underground strategic petroleum reserve (SPR) caverns in bedded rock salt," Energies, vol. 13, no. 7, p. 1565, 2020.

[11] X. Wang, W. Yuan, Y. T. Yan, and X. Zhang, "Scale effect of mechanical properties of jointed rock mass: a numerical study based on particle flow code," Geomechanics and Engineering, vol. 21, no. 3, pp. 259-268, 2020.

[12] H. Huang, T. BabadagliLin, X. Chen, H. Li, and Y. Zhang, "Performance comparison of novel chemical agents for mitigating water-blocking problem in tight gas sandstones," SPE Reservoir Evaluation \& Engineering, pp. 1-9, 2020.

[13] G. Harry, "Design of reinforcing piles to increase slope stability," Canadian Geotechnical Journal, vol. 32, no. 5, pp. 808-818, 1995.

[14] G. B. Shi, J. H. Yang, S. X. An, and N. Li, "Collapse mechanism analysis of steep-high rock slope of Shiquan hydropower station and reinforcement design," Rock and Soil Mechanics, vol. 7, pp. 1186-1192, 2004, in Chinese.

[15] J. Y. Dong, J. H. Yang, F. Q. Wu, D. Wang, and G. X. Yang, "Research on collapse of high cutting slope with horizontal soft-hard alternant strata in Three Gorges reservoir area," Rock and Soil Mechanics, vol. 31, pp. 151-157, 2010, in Chinese.

[16] P. Lin, X. Liu, W. Zhou, R. Wang, and S. Wang, "Cracking, stability and slope reinforcement analysis relating to the Jinping dam based on a geomechanical model test," Arabian Journal of Geosciences, vol. 8, no. 7, pp. 4393-4410, 2015.

[17] M. C. He, C. Li, W. L. Gong, L. R. Sousa, and S. L. Li, "Dynamic tests for a constant-resistance-large-deformation bolt using a modified SHTB system," Tunnelling and Underground Space Technology, vol. 64, pp. 103-116, 2016.

[18] Q. Wang, M. C. He, J. Yang, H. K. Gao, B. Jiang, and H. C. Yu, "Study of a no-pillar mining technique with automatically formed gob-side entry retaining for longwall mining in coal 
mines," International Journal of Rock Mechanics and Mining Sciences, vol. 110, pp. 1-328, 2018.

[19] Z. G. Tao, C. Zhu, X. H. Zheng, and M. C. He, "Slope stability evaluation and monitoring of Tonglushan ancient copper mine relics," Advances in Mechical Engineering, vol. 10, pp. 1-16, 2018.

[20] Z. Tao, Y. Wang, C. Zhu, H. Xu, G. Li, and M. He, "Mechanical evolution of constant resistance and large deformation anchor cables and their application in landslide monitoring," Bulletin of Engineering Geology and the Environment, vol. 78, no. 7, pp. 4787-4803, 2019.

[21] M. He, W. Gong, J. Wang et al., "Development of a novel energy-absorbing bolt with extraordinarily large elongation and constant resistance," International Journal of Rock Mechanics and Mining Sciences, vol. 67, pp. 29-42, 2014.

[22] W. L. Gong, J. Wang, Y. X. Gong, and P. Y. Guo, "Thermography analysis of a roadway excavation experiment in $60^{\circ}$ inclined stratified rocks," International Journal of Rock Mechanics and Mining Sciences, vol. 60, pp. 134-147, 2013.

[23] Y. Zhang, S. J. Cao, N. Zhang, and Z. Z. Zhao, "The application of short-wall block backfill mining to preserve surface water resources in northwest China," Journal of Cleaner Production, vol. 261, pp. 57-68, Article ID 121232, 2020.

[24] F. Huang, H. Zhu, Q. Xu, Y. Cai, and X. Zhuang, "The effect of weak interlayer on the failure pattern of rock mass around tunnel-scaled model tests and numerical analysis," Tunnelling and Underground Space Technology, vol. 35, pp. 207218, 2013.

[25] P. F. Shan and X. P. Lai, "An associated evaluation methodology of initial stress level of coal-rock masses in steeply inclined coal seams, Urumchi coal field, China," Engineering Computations, vol. 37, no. 6, pp. 2177-2192, 2020.

[26] S. J. Friedmann, N. Taberlet, and W. Losert, "Rock-avalanche dynamics: insights from granular physics experiments," International Journal of Earth Sciences, vol. 95, no. 5, pp. 911919, 2006.

[27] A. K. Alzo'ubi, C. D. Martin, and D. M. Cruden, "Influence of tensile strength on toppling failure in centrifuge tests," International Journal of Rock Mechanics and Mining Sciences, vol. 47, no. 6, pp. 974-982, 2010.

[28] F. Bourrier, F. Berger, P. Tardif, L. Dorren, and O. Hungr, "Rockfall rebound: comparison of detailed field experiments and alternative modelling approaches," Earth Surface Processes and Landforms, vol. 37, no. 6, pp. 656-665, 2012.

[29] L.-q. Li, N.-p. Ju, S. Zhang, X.-x. Deng, and D. Sheng, "Seismic wave propagation characteristic and its effects on the failure of steep jointed anti-dip rock slope," Landslides, vol. 16, no. 1, pp. 105-123, 2019.

[30] Q. Wang, B. Jiang, R. Pan et al., "Failure mechanism of surrounding rock with high stress and confined concrete support system," International Journal of Rock Mechanics and Mining Sciences, vol. 102, pp. 89-100, 2018.

[31] M. C. He and Z. B. Guo, "Mechanical property and engineering application of anchor bolt with constantre-sistance and large deformation," Chinese Journal of Rock Mechanics and Engineering, vol. 33, pp. 1297-1308, 2014, in Chinese.

[32] Z. G. Tao, Z. Zhu, W. S. Han et al., "Static tension test and the finite element analysis of constant resistance and large deformation anchor cable," Advances in Mechanical Engineering, vol. 10, no. 12, Article ID 1687814018810638, 2018.

[33] S. P. Ma, X. H. Xu, and Y. H. Zhao, "The GEO-DSCM system and its application to the deformation measurement of rock materials," International Journal of Rock Mechanics and Mining Sciences, vol. 41, no. 3, pp. 411-412, 2014.
[34] F. Hild and S. Roux, "Digital image correlation: from displacement measurement to identification of elastic properties-a review," Strain, vol. 42, no. 2, pp. 69-80, 2006.

[35] B. Pan, K. M. Qian, H. M. Xie, and A. Asundi, "Two-dimensional digital image correlation for in-plane displacement and strain measurement: a review," Measurement Science and Technology, vol. 20, no. 6, pp. 1-17, 2009.

[36] Y. Yu and S. T. Acton, "Speckle reducing anisotropic diffusion," IEEE Transactions on Image Processing: A Publication of the IEEE Signal Processing Society, vol. 11, no. 11, pp. 12601270, 2002. 